\title{
Vision Therapy for Binocular Dysfunction Post Brain Injury
}

\section{THESIS}

Presented in Partial Fulfillment of the Requirements for the Degree Master of Science in the Graduate School of The Ohio State University

\author{
By \\ Joseph Samuel Conrad, BS \\ Graduate Program in Vision Science
}

The Ohio State University

2011

\author{
Master's Examination Committee: \\ Marjean Taylor Kulp, OD, MS, Advisor \\ Michael Earley, OD, PhD \\ Nicklaus Fogt, OD, PhD
}




\section{Copyright by}

Joseph Samuel Conrad

2011 


\begin{abstract}
PURPOSE: To prospectively evaluate the effectiveness of home-based computer vergence therapy for treatment of binocular vision disorders in adults, ages 18-85, at least 3 months post brain injury. METHODS: Eligibility criteria included presence of binocular or accommodative dysfunction characterized by receded near point of convergence (NPC) ( $\geq 6 \mathrm{~cm}$ break), insufficient positive fusional vergence (PFV) at near (failing Sheard's criterion or $<15 \Delta$ blur or break), insufficient negative fusional vergence (NFV) at near $(<12 \Delta$ blur or break), reduced vergence facility with $12 \Delta \mathrm{BO} / 3 \Delta \mathrm{BI}$ at near $(<15 \mathrm{cpm})$, and/or below minimum expected amplitude of accommodation for age. All subjects were prescribed 12 weeks of home-based computer vergence therapy. Phoria (cover test), NFV at near, PFV at near, NPC, vergence facility, accommodative amplitude and facility (nonpresbyopes only), and symptoms (convergence insufficiency symptom survey [CISS]) were assessed at baseline and after 4, 8 and 12 weeks of prescribed therapy. ANOVA was used to evaluate change in each measure. Percent successful also was determined. RESULTS: Of the 19 subjects enrolled (mean age $45.4 \pm 12.9$ years), 15 suffered external mechanical trauma to the head, 3 suffered cerebrovascular accident, and 1 suffered from organic brain syndrome. Six subjects were lost to follow-up. The binocular profile of the cohort at baseline was orthophoria $(\mathrm{SD}=1.08)$ at distance, $7.11 \Delta$
\end{abstract}


$(\mathrm{SD}=5.19)$ exophoria at near, $\mathrm{NPC}$ break $=17.07 \mathrm{~cm}(\mathrm{SD}=10.56), \mathrm{NPC}$ recovery $=21.48$ $\mathrm{cm}(\mathrm{SD}=11.66)$, near $\mathrm{NFV}=12.33 \Delta(\mathrm{SD}=4.37)$, near $\mathrm{PFV}=8.80 \Delta(\mathrm{SD}=5.69)$, vergence facility $=4.06 \mathrm{cpm}(\mathrm{SD}=4.41)$, and $\mathrm{CISS}=31.12(\mathrm{SD}=12.93)$. ANOVA showed statistically significant improvement for NPC break $(\mathrm{p}=0.002)$ and recovery $(\mathrm{p} \leq 0.001)$, PFV blur $(p \leq 0.0001)$, break $(p \leq 0.0001)$, and recovery $(p \leq 0.0001)$, NFV blur $(p=0.047)$, break $(\mathrm{p}=0.008)$, and recovery $(\mathrm{p}=0.017)$, vergence facility $(\mathrm{p} \leq 0.0001)$, and CISS $(p \leq 0.0001)$. The percentage of patients who were classified as "successful" or "improved" was $69 \%$ for NPC ( $<6 \mathrm{~cm}$ or a decrease of $>4 \mathrm{~cm}), 77 \%$ for PFV $(>15 \Delta$ and passing Sheard's criterion or an increase of $\geq 10 \Delta), 77 \%$ for NFV ( $\geq 12 \Delta$ or an increase of $\left.\geq 6^{\Delta}\right), 69 \%$ for PFV and NFV, $92 \%$ for vergence facility ( $15 \mathrm{cpm}$ or an increase of 3 cpm), and $62 \%$ for CISS ( $<21$ or a decrease $\geq 10$ points).CONCLUSIONS: The majority of the $68 \%$ of subjects who completed the study experienced meaningful improvements in signs and symptoms. 


\section{Acknowledgments}

Thanks to Dr. Marjean Kulp, my advisor on this project for her patient guidance and tireless effort in the study design, subject recruitment, analysis of data, and editing of the thesis. I could not have finished the work without her. My gratitude overflows.

Thanks to Dr. Mike Earley and Dr. Nick Fogt for serving as committee members. They have greatly impacted me academically, clinically, and in research. I have gained as much from these two individuals as any educator under which I have studied.

Thanks to my parents and siblings who have encouraged me to stay the course and keep the faith. Thanks to my uncles and aunts, the Chapmans and Kurz', for providing the ideal environment in which to write the majority of this thesis during the last six months of my optometry rotations.

And thanks to my wife Samantha, whose unwavering support and constant edification enables me in every aspect of life. I thank God every day for you and our beautiful daughter, Julianna. I love you both. 


\title{
Vita
}

\begin{abstract}
May 2003 ........................................................... Avon Park High School
December 2006................................................S. Pre-Medicine cum laude, Clearwater Christian College
\end{abstract}

\section{Fields of Study}

Major Field: Vision Science 


\section{Table of Contents}

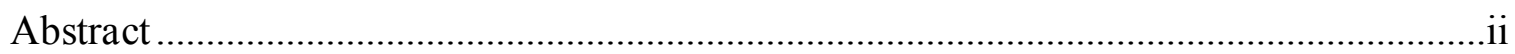

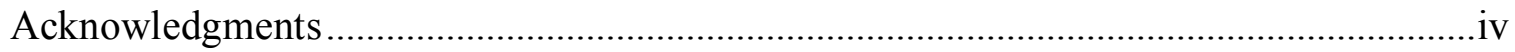

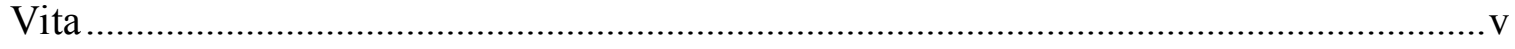

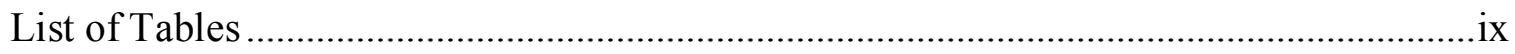

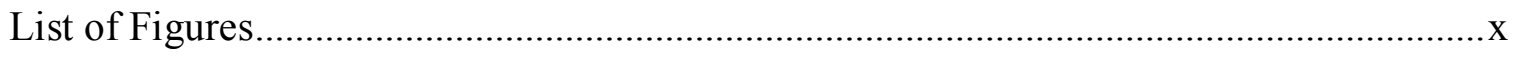

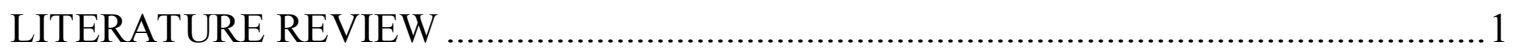

Traumatic Brain Injury Definition ........................................................................

Age as a Factor in Traumatic Brain Injury ..............................................................

Pathophysiology of Traumatic Brain Injury .............................................................

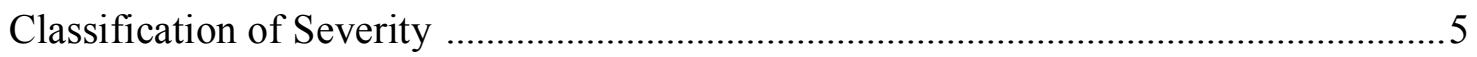

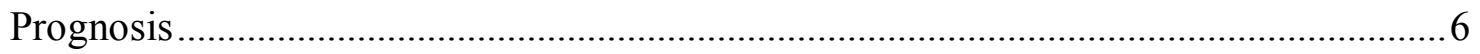

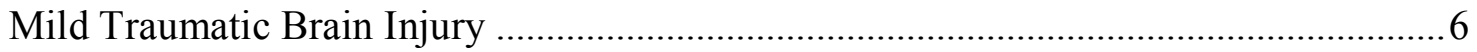

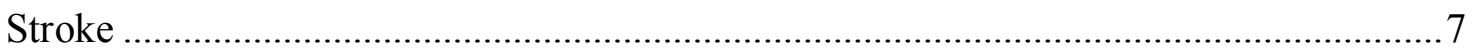

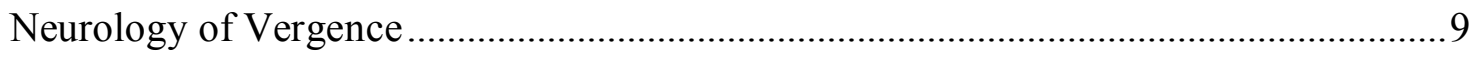

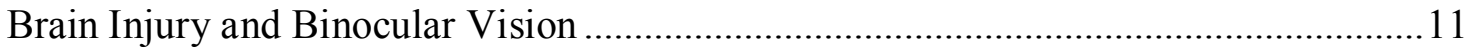


Treatment of Brain Injury Induced Binocular Dysfunction

Brain Injury Recovery: Models of Neuroplasticity

METHODS

Subjects

Study Aims

Inclusion and Exclusion Criteria

Recruitment of Subjects

Testing Procedures

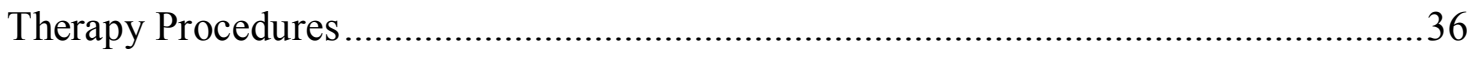

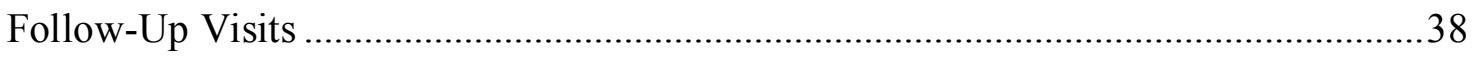

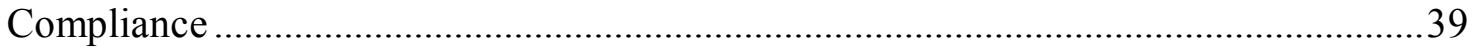

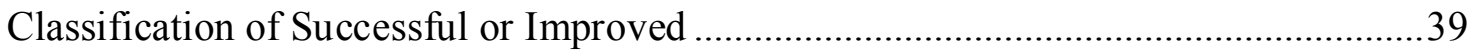

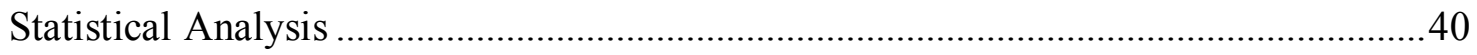

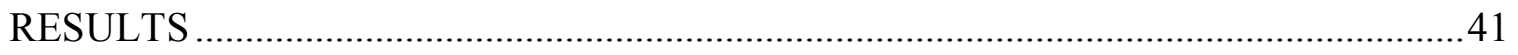

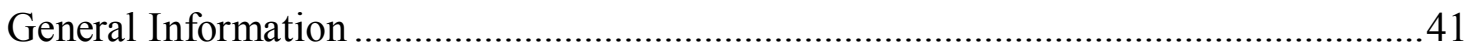

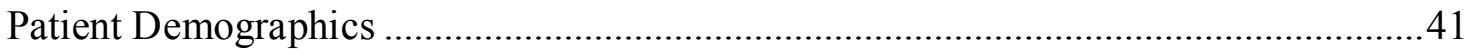

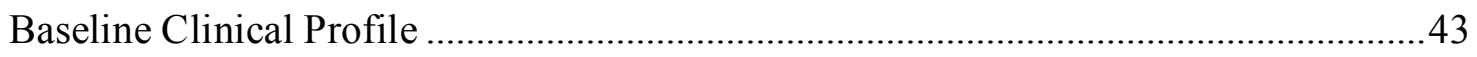

Clinical Profile Post Vision Therapy …………………….........................................45

Analysis of Clinical Measures .....................................................................................48 
Kinetics of Change

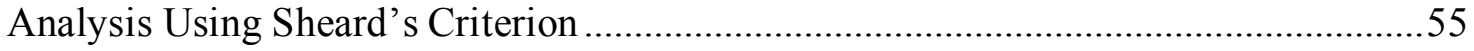

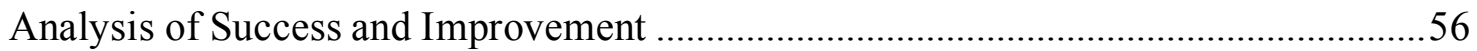

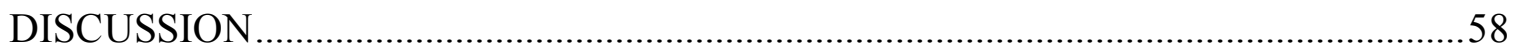

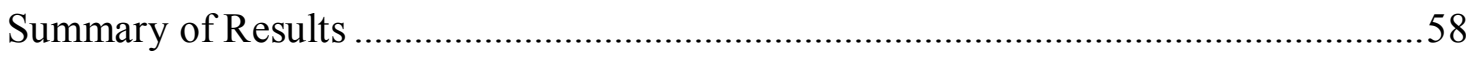

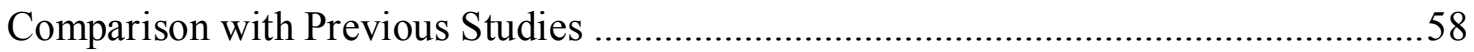

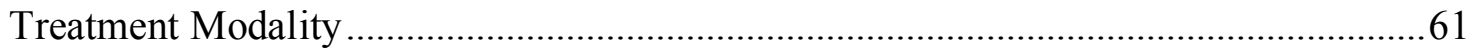

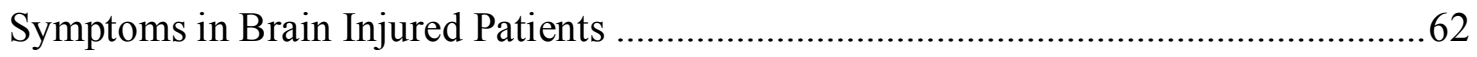

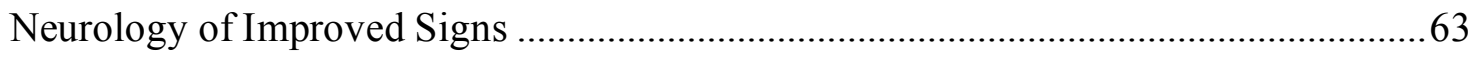

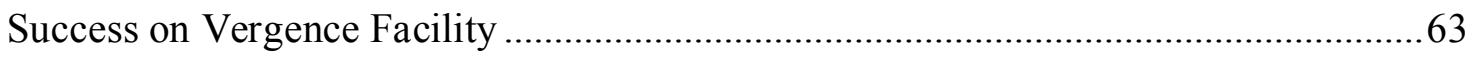

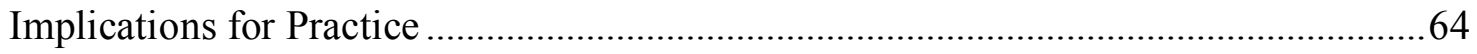

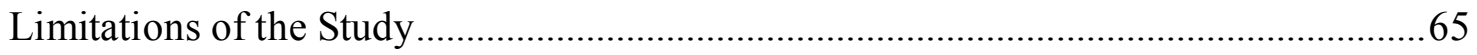

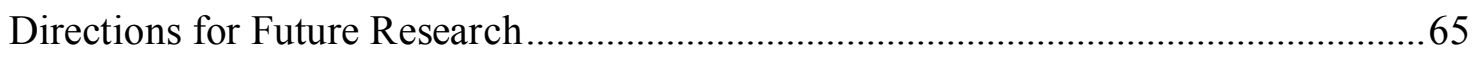

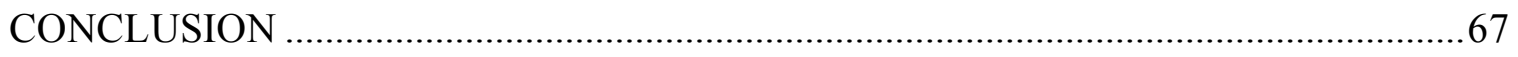

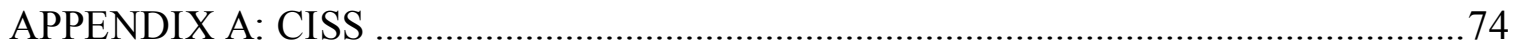

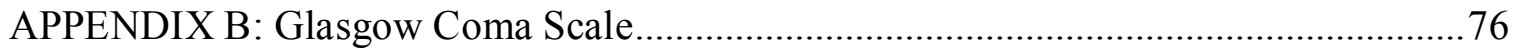




\section{List of Tables}

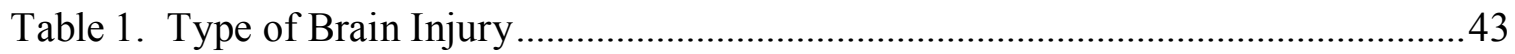

Table 2. Clinical Measures - Completed vs. Lost to Follow Up ....................................45

Table 3. Baseline and Outcome Visit Values ................................................................4

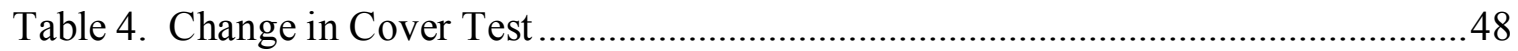

Table 5. Change in Negative Fusional Vergence ...........................................................49

Table 6. Change in Positive Fusional Vergence .............................................................50

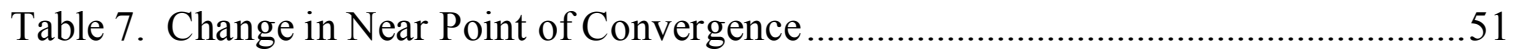

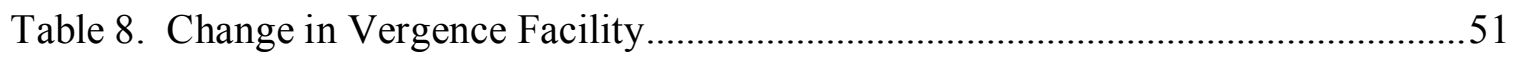

Table 9. Change in Convergence Insufficiency Symptom Survey .................................52

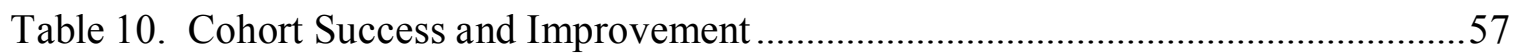




\section{List of Figures}

Figure 1. Randot Stereo Test Booklet With Polarized Glasses .........................................28

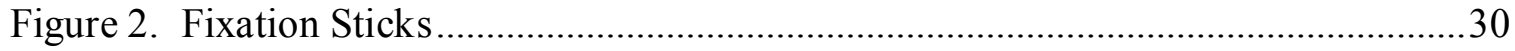

Figure 3. Astron International (ACR/21) Acommodative Rule ......................................31

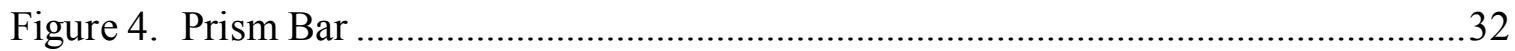

Figure 5. $12 \Delta \mathrm{BO} / 3 \Delta \mathrm{BI}$ Vergence Facility Prism ............................................................ 34

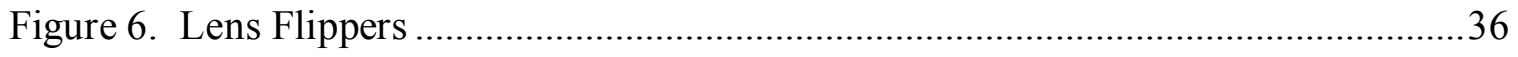

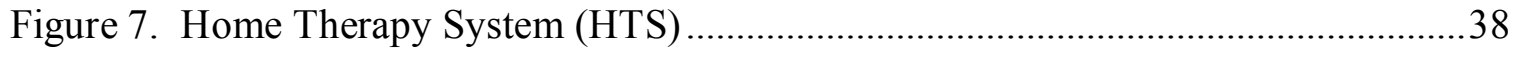

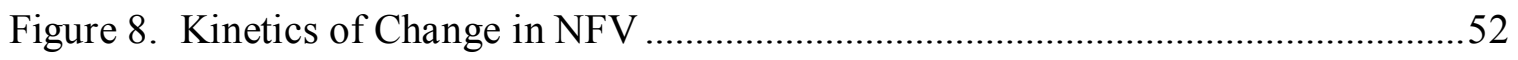

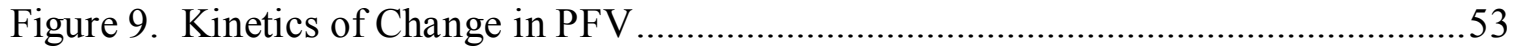

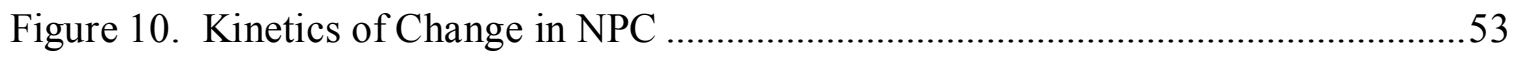

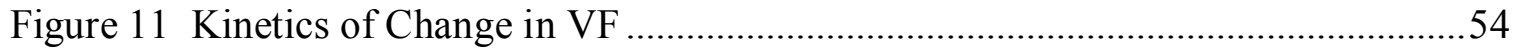

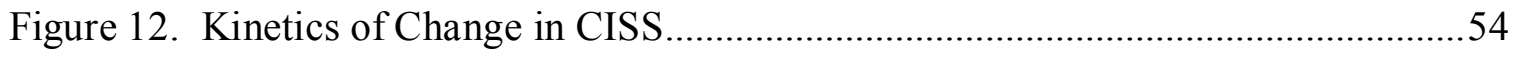

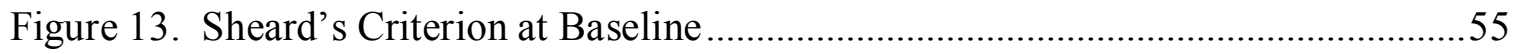

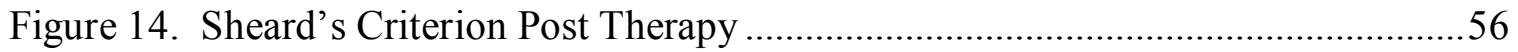




\section{LITERATURE REVIEW}

\section{$\underline{\text { Traumatic Brain Injury Definition }}$}

Brain injury is a general term used to describe an event in which an individual sustains insult to the brain. The total of all brain injuries is usually subcategorized into groups based on the type of insult to the brain tissue. Nearly every paper, article, book chapter, or comprehensive textbook on traumatic brain injury (TBI) begins with a definition. However, the sheer number of definitions is overwhelming. Some only include certain groups based on specifics of the cause of the trauma. Others form a definition based on acute phase signs and symptoms. Others reduce the definition to an absolute minimum, such as "trauma which carried some risk of damage to the brain. "' A plethora of definitions yields a plethora of interpretations. This creates an obvious hindrance to any epidemiological study regarding brain injury. In their textbook Medical Rehabilitation of Traumatic Brain Injury, Horn and Zasler recognize the TBI definition from the National Head Injury Foundation (NHIF) as functional and comprehensive. It states:

Traumatic head injury is an insult to the brain, not of degenerative or congenital nature but caused by an external physical force, that may produce a diminished or altered state of consciousness, which results in impairment of cognitive abilities or physical functioning. It can 
also result in the disturbance of behavioral or emotional functioning.

These impairments may be either temporary or permanent and cause partial or total functional disability or psychosocial maladjustment. ${ }^{1,2}$

The Demographics and Clinical Assessment Working Group of the International and Interagency Initiative toward Common Data Elements for Research on Traumatic Brain Injury and Psychological Health strives to present an all encompassing definition in the simplest, most concise form possible. They propose TBI be defined as an alteration in brain function, or other evidence of brain pathology, caused by an external force. ${ }^{3}$ This classification includes external mechanical force to the head, which may be penetrating or non-penetrating. The Brain Injury Association of America reports that approximately 1.4 million Americans are known to suffer from TBI every year. Of these, 50,000 die, 235,000 are hospitalized and 1.1 million are treated and released from the emergency room. The number of individuals who have a qualifying TBI event and do not seek care is not known. Falls account for the largest percentage of TBI (28\%), while motor vehicle accidents are second (20\%). In 2000, direct and indirect costs of traumatic brain injuries totaled a staggering $\$ 60$ billion. ${ }^{57}$ In 1999 , the Centers for Disease Control (CDC) reported that approximately 3.17 million Americans who have sustained a TBI have deficits in completing activities of daily living (ADLs). ${ }^{4}$

\section{Age as a Factor in Traumatic Brain Injury}

One of the most common ways to subcategorize TBI patients is by age. Many studies have shown that the young adult years, typically age 15 to 24 , demonstrate the highest incidence of TBI. When etiology is evaluated, age groups are easily established. 
For instance, falls are the most common cause of TBI in children. Motor vehicle accidents dominate the middle years of life with respect to brain injury. Late in life, falls again become the prominent etiology. Mortality rates also respect age groups as elderly individuals lead the way in lethal brain injury events followed by the young adult age group. It is surmised that the elderly are more vulnerable to succumb to a moderate injury, while the severity of injury in motor vehicle accidents in the young adult age group tends to be greater. ${ }^{1}$

\section{Pathophysiology of Traumatic Brain Injury}

In discussion of the pathophysiology of TBI, it must first be divided into primary and secondary injury. Primary injury refers to the trauma that physically occurs at the time of the event. This could include disruption of the brain tissue by a bullet from a gunshot, fragments of skull, stresses of acceleration-deceleration impact, and so on. Primary injury usually consists of cortical disruption, axonal injury, vascular injury, or hemorrhage. Kochanak, et al points out that axonal injury often occurs in conjunction with vascular injury simply by anatomical association. ${ }^{9}$ This type of primary injury is seen on neuro-imaging as petechial hemorrhages and has been termed diffuse axonal injury (DAI). Recently, the term DAI has been replaced by some with traumatic axonal injury (TAI) because the damage is localized to specific areas of the brain and is thus not considered to be truly diffuse. 5,6

If a hematoma or elevated intracranial pressure (ICP) is not noted on a patient, DAI is the most commonly cited injury in cases of disability and depressed levels of consciousness secondary to TBI. While axonal injury is commonly reported to be present 
in individuals with Glasgow Coma Scale (GCS) scores of less than 12, the mildest classifications of head trauma (GCS scores of 13 to 15 ) almost certainly contain this type of injury as well. ${ }^{6}$ Thus, it is reasonable to surmise that those who suffer brain injuries which may not seem to necessitate evaluation or treatment can experience the effects of widespread axonal injury. DAI is divided into three categories for purposes of grading the injury. Grade 1 DAI will reveal scattered axonal bulbs (secondary to retraction of the axons) in the white matter. DAI is upgraded to grade 2 in the presence of a lesion to the corpus callosum, and grade 3 signifies the presence of a rostral brainstem lesion that usually will result in permanent coma or vegetation. ${ }^{8}$ However, DAI as the dominant theory of lasting consequences of brain injury has been weakened in recent years. Studies investigating the biochemistry of brain injury suggest a temporary dysfunction of neurons due to neurochemical cascades incited by the trauma. Thus, cell death, at least in mild brain injury, does not account for the temporary clinical signs because the neuronal injury resolves. $^{7}$

Secondary injury refers to effects from the primary injury that ensue within the subsequent hours and days. Following the primary trauma, metabolic cascades ensue. There are several broad categories of secondary injury including ischemia, excitotoxicity, cell death cascades, cerebral edema, axonal injury, and inflammation and regeneration. ${ }^{9}$ In the brain injury research community, it was previously believed that axonal injury (usually by shearing forces) was simply a primary injury and could be treated as such. However, more recent findings have reported a secondary injury cascade which may account for the majority of all axonal injuries. ${ }^{10}$ Two models of secondary axonal injury, or secondary axotomy, have been offered, both of which are believed to occur in brain 
injuries, differing only in extent. The first proposes that calcium influx due to increased permeability along the neuron is the inciting event for damage. The second suggests impairment of axoplasmic flow due to cytoskeletal abnormality is the cause for axonal injury. ${ }^{9}$

\section{Classification of Severity}

There are several methods with which brain injury severity is graded. Prognosis, treatment plan, and communication with the patient and family hinges, in part, on the classification used. Perhaps the most common form of grading brain injury severity is the GCS. The GCS score is derived from three different categories - eye opening, best motor response, and verbal response. The sum of the three subcategorical scores yields the overall score. A score of 15 is perfect and a score of 3 is completely unresponsive. The GCS allows the practitioner to assess the severity of the brain injury as minor, moderate, or severe with scores of $13-15,9-12$, and 8 or less, respectively. ${ }^{1}$ See Appendix B for a copy of the GCS.

Length of time in coma, or unconsciousness, was previously used as an indicator of severity, with six hours of coma or more classified as a severe brain injury. However, with further investigation, it has been found that there is not necessarily a direct relationship between severity of brain injury and length of coma. It is common for an individual to experience a short duration of coma followed by a lifetime of lasting effects. Other widely utilized tools for rating brain injury severity include grading systems for injury, the Abbreviated Injury Scale, the Revised Trauma Score, and grading of posttraumatic amnesia. ${ }^{1}$ 


\section{$\underline{\text { Prognosis }}$}

Expected prognosis is of utmost importance during the days following a TBI because it influences choice of treatment, referral to tertiary care, and communication to the patient and family. In light of this, many studies have been conducted to attempt to identify the best prognostic indicators. Among the most reliable are age, pupil abnormalities, and the Glasgow Coma Scale. Among the least reliable are magnetic resonance imaging (MRI) and evoked potentials. ${ }^{11}$

\section{$\underline{\text { Mild Traumatic Brain Injury }}$}

According to one source, mild TBI is diagnosed if the patient meets four criteria. These criteria are history of a TBI with a GCS score of 13 or greater, coma or posttraumatic amnesia not exceeding twenty minutes in duration, hospitalization 48 hours or less, and lack of brain contusion. Another source provides an alternative to diagnosing mild TBI by requiring the patient to at least have one of the following: any loss of consciousness, any amnesia for events immediately surrounding the accident (not exceeding 24 hours), alteration in mental state not exceeding 30 minutes in duration, GCS score of 13-15 thirty minutes after the incident, or posttraumatic amnesia of 24 hours or less. ${ }^{12}$ While the strictness of diagnostic criteria may differ somewhat across authorities, it is important to note the similarities and draw valuable information regarding mild TBI in so doing. Frank abnormalities on neuroimaging diagnostics are

rare in mild TBI. ${ }^{5}$ It is also crucial to understand that mild TBI excludes events that have skull fracture and major hemorrhage involved. Typically, stroke, anoxia, tumor, inflammation, toxicity, and dementia are excluded from mild TBI as well. 
An emergency room report in 2005 stated that 56/100,000 people in the United States are evaluated for an isolated mild TBI each year. ${ }^{5}$ Most are treated and released from further care. It should be noted that it is very difficult to predict the actual number of mild TBIs that occur each year due to the choices of some individuals to forego evaluation and treatment. One researcher estimated that $14 \%$ of individuals who sustain a mild TBI are seen in outpatient clinics and offices and approximately $25 \%$ do not seek care at all. ${ }^{13}$ Mild TBI is usually self-limiting and permanent effects tend to be rare, but often symptoms will linger past what is thought to be the natural history of a few months. This is commonly known as the post concussive syndrome. ${ }^{71}$ Visual symptoms, for example, are commonly experienced months and years after a TBI. ${ }^{13}$

\section{Stroke}

Cerebrovascular accident (CVA), commonly referred to as stroke, is the third leading cause of death in the United States and among the leading causes of adult disability. The cause of stroke can be ischemic (blockage of a blood vessel by atherosclerosis, thrombus, or embolus) or hemorrhagic (often by a burst aneurysm). The American Heart Association reports that there are 6.4 million stroke survivors alive today. Of these, over $60 \%$ are female. Studies show that almost 800,000 strokes occur each year, with over $75 \%$ of these as first occurrence strokes. The death rate from stroke declined by over $33 \%$ during the ten year span from 1995 to $2005 .^{15}$

Visual dysfunction following a stroke is very commonly seen clinically and can be devastating to ADLs. It has been estimated that approximately $30-85 \%$ of patients who sustain a CVA experience some type of visual dysfunction. ${ }^{17,18}$ Visual dysfunction 
following such an injury can be relatively easily categorized into sensory, motor, and visual perceptual. ${ }^{16}$ While decreased visual acuity certainly falls into the sensory category of visual dysfunction, it is the visual field deficits that are classically characteristic of a stroke. Visual field losses such as homonymous hemianopias and quadrantanopias commonly show up on visual field testing of stroke patients. Homonymous hemianopias are visual field defects that are present in both eyes, respect the vertical midline, and affect either the right or the left field. Any lesion along the visual pathways posterior to the optic chiasm will affect both eyes, in the same spatial field of vision. The more posterior the lesion is, the more congruous the visual field defect. Anatomically, fibers from the optic nerves project posteriorly, which meet and partially decussate at the optic chiasm, then become the optic tracts. ${ }^{47}$ The result of the partial decussation is that fibers from the nasal retina of one eye travel along with fibers from the temporal retina of the fellow eye. Simply put, damage anywhere along this path will cause corresponding visual field defects in temporal and nasal field, respectively. When mapped out in space, the patient will experience visual field dysfunction to the left (right sided stroke) or to the right (left sided stroke). A quadrantanopia is a type of visual field defect that is limited to one quadrant of the field that occurs as a result of the anatomy of the visual pathway posterior to the lateral geniculate nucleus (LGN). As fibers leave the LGN, the inferior fibers track through the temporal lobe as the loop of Meyer. A temporal lobe stroke can manifest visually as a contralesional superior homonymous quadrantanopia. Similarly, the superior fibers pass through the parietal lobe and when damaged can cause a contralesional inferior defect limited to one quadrant of visual field. ${ }^{44}$ 
Motor visual deficits following a CVA are common as well. ${ }^{19}$ Three of the twelve cranial nerves (III, IV, and VI) innervate the extraocular muscles. An infarction involving one of these nerves could cause a muscle palsy or paresis with associated diplopia. Conjugate eye movements (saccades and smooth pursuits) can exhibit dysfunction if their neurologic control centers are damaged by the stroke.

\section{Neurology of Vergence}

Vergence eye movements are classified as disconjugate eye movements, in that during vergence the eyes are moving in opposite directions. This is opposite the conjugate eye movements, which include saccades and smooth pursuit. Several types of vergence eye movements have been described, including tonic, proximal, fusional, and accommodative. The stimulus to fusional vergence is retinal disparity. Disparity of an image on the retinas of the two eyes causes diplopia, which drives the fusional response. The stimulus to accommodative vergence is blur. If an object of interest appears blurry to the retina, an eye movement to that object will include an increase or decrease in accommodation, which will drive a linked vergence response. This link between accommodation and vergence can be easily demonstrated by covering one eye and having the subject change focus from distance to near. As the subject accommodates to the near target, the eye under cover will converge in tandem. Schor's cross-link model of vergence and accommodation is a widely accepted model of this interaction with the accommodative convergence / accommodation (AC/A) and convergence accommodation

/ convergence $(\mathrm{CA} / \mathrm{C})$ ratios being responsible for the crossing effects. ${ }^{58,59}$ 
Premotor control of vergence eye movements is contained, in part, in the mesencephalic reticular formation near the oculomotor (III) nucleus. Three types of cells have been identified there: tonic cells which are related to vergence angle, burst cells which are related to vergence velocity, and tonic-burst cells which are related both to vergence angle and velocity. Motor control is carried out by the medial rectus subnucleus and abducens nucleus (VI), both of which are involved in convergence and divergence.

Cerebellar control of vergence has been reported in light of vergence dysfunction in the presence of acute cerebellar lesions. The cerebellar flocculus and vermis are known to be involved in vergence, but the specifics of the neurology are not completely understood.

Cortical control of vergence may be even less elucidated. However, a recent paper reporting on correlating the effect of vision therapy on convergence insufficiency in adults using functional magnetic resonance imaging (fMRI) showed widespread cortical activation with vergence eye movements. Dorsal lateral prefrontal cortex, frontal eye fields, supplemental eye fields, medial frontal gyrus, precuneus, Brodmann areas 39 and 40, parietal eye fields, and inferior parietal area were all identified areas of cortical involvement. Extensive brainstem and cerebellar involvement was noted as well. ${ }^{60}$ Treatment of vergence dysfunction in this study showed a significant correlation between improvement on clinical signs (NPC, PFV, and near dissociated phoria) and increase in cortical, brainstem, and cerebellar activity on functional neuroimaging. 


\section{Brain Injury and Binocular Vision}

Vision is a complex phenomenon in which light, in varying luminance, color, and contrast is received by the neural tissue in the retina and transmitted to many different areas of the brain where it is integrated and synthesized into a single percept. It is of no surprise that any given damage from a brain injury could have a significant impact on vision.

Vision has been described as being mediated by a bimodal process. One process, the focal visual process, is mediated by the parvocellular retinal ganglion cells. ${ }^{20}$ This aspect of vision mainly accounts for central vision and visual acuity. Its purpose is to focus on a specific target and to provide sharp vision for that task. The peripheral process, also known as the ambient visual process, is mediated by the magnocellular retinal ganglion cells. ${ }^{20,21}$ Put most simply, this process is responsible for peripheral awareness of surroundings and to respond quickly when the peripheral environment changes. This process must be inhibited somewhat for purposes of visual attention. If the ambient visual process is not actively inhibited to some degree, then the individual will become painfully aware of every small detail of the surroundings. Examples of this may include low levels of background conversation in a crowded restaurant or a flickering fluorescent light on the ceiling. This is often the case in the brain injured patient. Visual attention in the higher levels of visual processing can be damaged, severely affecting quality of life in some cases. Binasal occlusion and base-in prism are often used to treat a disorder such as this. It is thought that the combination of binasal occlusion and a small amount of base-in prism stabilizes the ambient visual process (magnocellular mediated vision), alleviating some of the common symptoms. This was demonstrated by measuring 
visual evoked potentials (VEP) in a sample of brain injured individuals before and after application of base-in prism and binasal occlusion. The amplitude of the VEP was increased with the treatment. Interestingly, the control group (without brain injury) showed a decrease in VEP amplitude upon application of the base-in prism and binasal occlusion. Thus, the exact same change to the visual stimulus seemed to organize the visual process in the injured group and disrupt the visual process in the healthy group. ${ }^{22,25}$ However, the base-in prism may have been helpful to the brain injured group simply due to the higher percentage of exophoric individuals relative to the control group.

Dysfunction of binocular vision has been shown to be one of the most common visual consequences of the insult in the brain injury population. Several reviews of this patient base showed high rates of deficits in vergence, accommodation, and oculomotor eye movements. ${ }^{40,41,42,43}$ One of the largest optometric studies of brain injury was conducted at the State University of New York College of Optometry. In a review of 220 medical records, Ciuffreda, et al reported signs, symptoms, and treatment of 160 mild TBI patients and $60 \mathrm{CVA}$ patients. ${ }^{23}$ The mean age of the TBI subgroup was 44.9 years, while the mean age of the CVA subgroup was 61.2 years. Loss of balance was reported in over $55 \%$ of both subgroups. Dizziness was common in both subgroups, but more so in the TBI subgroup. Vertigo was also a common symptom in both, being reported in $28 \%$ of TBI patients and 15\% of CVA patients. Visual symptoms were prevalent in both groups. In TBI, eyestrain with near vision tasks (52\%), increased light sensitivity (50\%), headaches with near vision (44\%), and near vision blur (44\%) were the most common visual symptoms. In the CVA subgroup, near vision blur (40\%), eyestrain with near vision tasks (38.3\%), loss of place while reading (33.3\%), and distance vision blur 
(31.7\%) were the most common visual symptoms. The most prevalent medical history complaints in the TBI subgroup were muscle aches and joint pain (48\%), numbness or weakness (44\%), history of depression (40\%), and gastrointestinal dysfunction (26.3\%). In the CVA subgroup, numbness or weakness (55\%), hypertension (52\%), muscles aches and joint pain (36.7\%), and cardiovascular problems (32\%) were the most common findings.

The same medical records were reviewed for prevalence of binocular dysfunction. It was found that there was a much higher incidence of binocular dysfunction in the brain injury cohort than in the non-brain injury cohort. For instance, deficits of vergence were present in $56 \%$ of the TBI group and $37 \%$ of the CVA group, with convergence insufficiency being the most common type. In contrast, it was reported that a standard non-presbyopic clinical population had a prevalence of convergence insufficiency of $4 \%$. A higher prevalence of oculomotor dysfunctions were reported as well. Deficiency in accommodation was present in $41 \%$ of TBI patients and $12.5 \%$ of CVA patients with accommodative insufficiency and accommodative infacility being the most common types, respectively. Versional dysfunction was prevalent in more than half of both groups with $51 \%$ of TBI patients and $57 \%$ of CVA patients affected. Deficits of saccades were the most common type in both subgroups. Strabismus was present in $26 \%$ of TBI with greater frequency at near, while strabismus was present in 37\% of CVA with greater frequency at distance. A similar number of TBI and CVA patients were found to have constant versus intermittent and unilateral versus alternating strabismus. Exo deviations greatly outweighed eso deviations and approximately half had a vertical component to the 
strabismus. Convergence insufficiency was the single most common oculomotor dysfunction found in this review, being seen in $40 \%$ of those with brain injury.

Overall, it was found that oculomotor dysfunction was present in $90 \%$ of TBI patients and $86 \%$ of patients who suffered cerebrovascular accident. These numbers represent a 4.5 times increase in oculomotor dysfunction frequency when compared to a symptomatic non-brain injured group. ${ }^{54}$

Other studies reinforce Ciuffreda's findings from the review of 220 brain injured patients. In 1989 , Cohen reported finding convergence insufficiency in $42 \%$ of brain injured patients at three years' follow up. Convergence insufficiency was found to have statistically significant associations with longer periods of coma, presence of cognitive disturbances, and difficulty finding work in the open market. It was concluded that the lingering nature of convergence insufficiency years after the initial trauma suggests a permanent damage to the mesencephalon, cerebellum, and cortex. ${ }^{24}$

In 1995, Lepore conducted a retrospective review of brain injury patients and found trochlear nerve palsies to be the most common nuclear or infranuclear cause for traumatic diplopia, while convergence insufficiency was the most common cause of supranuclear traumatic diplopia. ${ }^{25}$

Sabates et al reviewed 181 medical records to investigate neuro-ophthalmological sequelae of closed head trauma (over half of cases reviewed were secondary to motor vehicle accidents). They found that $88 \%$ had visual acuity of $20 / 20$ or better and $33 \%$ had suffered a cranial nerve palsy, with $75 \%$ of those resolving spontaneously. ${ }^{26}$

Post trauma vision syndrome (PTVS) has gained popularity in the field as a term to describe the constellation of signs and symptoms that often accompany a brain injury. 
Signs include exotropia, accommodative dysfunction, convergence insufficiency, low blink rate, spatial disorientation, poor fixations and pursuits, and unstable ambient vision (magnocellular mediated vision). Symptoms of PTVS include possible diplopia, stable objects appearing to move, poor concentration, poor attention, staring, poor visual memory, photophobia, asthenopia, poor balance, poor coordination, and poor posture. ${ }^{22,45}$ Padula, et al also describes the visual midline shift syndrome (VMSS). ${ }^{27,45}$ The human body has multiple systems for maintaining balance and posture and for accurate, smooth movements in the individual's surroundings. Proprioceptors in skeletal muscle throughout the body give feedback about environmental interaction based on stretch of the fibers, the vestibular system in the inner ear is finely tuned to sense changes in motion and head posture, and sensory input from the ambient visual system to the cerebellum and mesencephalon support the brain's ability to coordinate the body's sense of position and balance. The complex integration of data from these systems enables the individual to achieve complex interaction with the environment. Thus, a sense of subjective straight up and straight ahead is formed. An individual should be able to egocentrically identify where horizontal, vertical, and anterior-posterior axes intersect. This point becomes a reference for balance and posture. Vision seems to be the primary system in establishing this perception, so a brain injury that disrupts the ambient visual process will have a direct impact on the essential balance and postural abilities. It has long been observed that patients who suffer a hemianopsia, hemiparesis, or both may exhibit a postural shift away from the affected side. It was assumed that this was solely the result of a lack of motor or neurological function to the muscles on that side of the body. However, upon further investigation of patients with hemianopsia with or without hemiplegia, it was 
found that a clinically identifiable shift in the perception of egocentric midline occurred. By passing an object in front of the patient and asking him to respond when it was directly in front of him, the observer found that the midline was displaced away from the side of the hemianopic visual field loss. The shift was seemingly in place to compensate for the half of the visual world that was missing. The phenomenon was termed visual midline shift syndrome, or visual ataxia. Padula argues that it occurs secondary to a compression or expansion of the ambient visual process and that the midline can shift along the lateral or the anterior-posterior axis. In reference to physical rehabilitation, it is strongly advisable to determine if a patient is suffering from VMSS before attempting to correct such a corresponding postural shift. ${ }^{45}$ It has been demonstrated that yoked prisms are an effective option for correcting VMSS in the brain injured population. ${ }^{28}$

Visual neglect, also known as contralesional hemispatial neglect, is a dysfunction of visual perception and attention that may occur following a stroke. It is most closely associated with right inferior parietal lobe involvement, which leads to a condition in which the individual does not seem aware of objects in the contralateral visual field. ${ }^{62}$ It is important to note that diagnostic visual field testing in that hemifield shows a clear field in patients with neglect. There is some controversy regarding the specific location in the brain that is involved in visual neglect. While the posterior parietal lobe, especially near the tempero-parietal junction, has been accepted as one major area of involvement, one study of middle cerebral artery stroke patients has implicated the superior temporal gyrus on the surface of the right hemisphere. ${ }^{63}$ However, the author of one study used high resolution MRI to map out the lesions of middle cerebral or posterior cerebral artery stroke patients $(\mathrm{n}=35)$ with or without visual neglect. ${ }^{64}$ The location of involvement in all 
the neglect patients with middle cerebral lesions was the angular gyrus of the inferior parietal lobe with the superior temporal gyrus being damaged in only half of these patients. The location of involvement in all the neglect patients with posterior cerebral lesions was the parahippocampal region on the surface of the temporal lobe. The results of Bird's study also agreed with findings of parahippocampal involvement in posterior

cerebral stroke. ${ }^{65}$ The posterior cerebral patients without neglect did not have damage to this area. Because this study only found a 50\% involvement of the superior temporal gyrus in patients with neglect, the results of Karnath's study were not readily repeatable. Protocols in imaging technique were cited by Mort as potential reasons for this discrepancy. Visual neglect is a common dysfunction of visual attention following a stroke (especially middle and posterior cerebral arteries) and may not be elicited by case history or visual field testing. Simple tests of neglect have been widely used. One of the most common types includes the drawing of 30 short vertical lines in various locations on a sheet of paper. ${ }^{66}$ The patient is then asked to draw lines perpendicular through each of the vertical lines. The patient's ability to attend to the entire page can be easily analyzed in most cases. Deficits in motor ability, however, may inhibit the completion of this simple test.

\section{$\underline{\text { Treatment of Brain Injury Induced Binocular Dysfunction }}$}

A joint policy statement from the American Academy of Optometry and the American Optometric Association was published for eye care practitioners and the lay public in regard to optometric care of the patient with acquired brain injury. ${ }^{46}$ It begins by reinforcing the known fact that vision problems are common in the brain injury 
population and underscores some of the most common signs and symptoms. Prevalent signs that are noted include abnormal body posture, balance and coordination problems, closing or covering one eye, eye misalignment, head tilt or turn, poor judgment of depth, and difficulty localizing objects in space. Common symptoms include blurred vision, confusion when performing visual tasks, dizziness or vertigo, difficulty reading, double vision, eyestrain, headaches, inattention of vision, and visual fatigue. The disorders that may account for these signs and symptoms following brain injury include accommodative dysfunction, non-strabismic disorders of binocular vision, ocular motility disorders, strabismus, reduced visual acuity, visual field loss, and visual information processing disorders. In light of the clinical presentation of these patients and the impact of these disorders on ADLs, the policy statement declares that optometric evaluation and management can be of significant value. The initial evaluation may include one or more of the following: comprehensive exam, sensorimotor exam, low vision exam, analysis of cerebral function relative to visual information processing, extended visual field evaluation, and electrodiagnostic testing. The information from these types of assessments will enable the optometrist to assist in the overall rehabilitation of the brain injured patient. Treatment options may include a unique combination of lenses, prisms, occlusion, low vision devices, and vision therapy.

Randomized clinical trials have recently been published in regard to the most effective treatment for convergence insufficiency, one common binocular dysfunction. ${ }^{30}$, ${ }^{55}$ The Convergence Insufficiency Treatment Trial (CITT) group found that vergence/accommodative therapy is effective in treating symptomatic convergence insufficiency in children age 9-17. ${ }^{29,30,31}$ The office-based therapy group showed the 
greatest improvement when compared to home-based therapy (traditional pencil push up therapy or computer vergence/accommodative therapy plus pencil push up therapy) and placebo therapy. ${ }^{32}$ The effect of treatment on signs and symptoms of CI were maintained at least one year after discontinuation of treatment. ${ }^{33}$ It also was found that improvement of signs of CI with therapy was more rapid than improvement in symptoms. ${ }^{34}$ The efficacy of vision therapy in adult populations has also been reported. ${ }^{35,36,55}$

Because dysfunction of binocular vision has been treated with orthoptic/vision therapy for many decades, it seems reasonable to use the same or similar treatment plans for these binocular vision disorders when they present subsequent to a brain injury. However, controlled, prospective clinical research is lacking regarding treatment of binocular dysfunction in the brain injury population.

In addition to the retrospective reviews of optometric evaluation of brain injury, a number of case studies regarding the treatment of binocular dysfunction secondary to trauma have been reported. Scheiman and Gallaway conducted a review of acquired brain injury patients seen and treated in their university based clinics and private practices. ${ }^{48}$ They selected nine cases to report that represented common brain injury presentations. In an effort to determine prognostic indicators, they included both successful and unsuccessful cases of vision therapy for brain injury. The authors identified four potential barriers to the success of each patient. They were cognitive and perceptual problems, visual field loss, excyclotorsion, and sensory fusion disruption syndrome. Of the five cases that had convergence insufficiency as the primary dysfunction, four achieved success and one did not. The one who was unsuccessful had cognitive, memory, and attentional problems secondary to the brain injury. The visual 
field loss may or may not have a significant impact on symptoms depending on the type of visual field loss and the task at hand. For instance, a right homonymous hemianopia will have a detrimental effect on reading while a superior quadrantanopia may not. Excyclotorsion is a common manifestation if the fourth cranial nerve is involved. The authors reported this to be a major barrier to success, but surgical intervention in one patient helped enable success to be attained. Lastly, sensory fusion disruption syndrome was an important negative prognostic indicator. Patients who were able to demonstrate random dot stereopsis at baseline seemed to be much more likely to succeed in vision therapy treatment than those who did not. It also was noted that the findings from these nine cases were consistent with Krohel's report that it is difficult to predict success or failure based on the type or severity of the patient's injury. ${ }^{37}$

\section{Brain Injury Recovery: Models of Neuroplasticity}

The classical model for education in neuroscience is describing the brain and associated neural tissue as that which has a period of development and organization during embryology, fetal development, and early childhood and a period of relatively static structure and function throughout the rest of life. Upon brain injury and recovery from the acute phase, one must "simply deal with" the post-traumatic state by adapting to situations and learning behavioral approaches, commonly referred to as "compensatory strategies. ${ }^{49}, 50$, $T$ This ideology was supported by neuroanatomical researchers and remains in large part to this day. Stein points out that the undisputed leader in neuroscience textbooks in the classroom, Principles of Neural Science ${ }^{51}$, only mentions the concept of plasticity once. $^{49}$ 
In attempting to lay out a functional definition for neuroplasticity, Stein goes on to state that most any observed change in the central nervous system has been accompanied by the term neuroplasticity. Everything from changes in Alzheimer's disease to axonal sprouting to alteration of neuroreceptors has carried the term along. It is helpful, then, to lay out a definition of neuroplasticity as it relates to brain injury. It may be beneficial to limit the use of neuroplasticity to “...verifiable examples of functional and adaptive recovery after brain injury... implying that it is possible to have... acute or chronic deficits which disappear spontaneously, or which can be reduced by pharmacological, physiological, surgical, or behavioral treatments over time. ${ }^{49}$, In the early 1990s, the topic of neuroplasticity began to become a major player in theories in neurology, rehabilitative medicine, and brain injury. Since then, the journal Restorative Neurology and Neuroscience has published periodic reviews of major segments on this topic, including Regulators of Peripheral Nerve Regeneration, Spinal Cord Neuroplasticity, and Visual Plasticity, Restoration, and Rehabilitation, to name a few. ${ }^{38,39}$ Concepts of neuroplasticity began to become fleshed out by way of functional neuroimaging. It was shown that on a cellular level synaptic firing changes, presynaptic vesicle release alteration, dendritic arborization, axonal sprouting, neuronal reorganization, latent synapses, and increased astrocyte activity were evident. ${ }^{49,53}$ Furthermore, neurogenesis was found in the olfactory bulb. ${ }^{53}$ Huang describes four major categories of neuroplastic change. The first is homologous area adaptation. This type of neuroplasticity is demonstrated when a brain injury impairs a certain function and that function is transferred to an area of the brain that is undamaged. The example she uses to describe area adaptation is that of an infant who suffered a right parietal lobe injury. The 
child later suffered from poor math and language skills which are abilities typically carried out by the left parietal lobe. It was concluded that although the individual sustained a right parietal lobe injury directly, he possessed an acquired left parietal lobe dysfunction due to interhemispheric competition. The second type of neuroplasticity is compensatory masquerade, which is described as utilizing a less efficient pathway to accomplish a task that was previously handled by the now damaged brain area. Under the traditional or highly conservative definition of neuroplasticity, compensatory masquerade would most likely not be included and would be delegated to the classic idea of behavioral tricks or learned compensatory mechanisms. The third type, cross-modal reassignment, occurs when an area of the brain that does not receive its designed input is "reallocated" to receive input of a different type. Perhaps the best example of this is individuals who become blind at a young age. It has been shown that the visual cortex in the occipital lobe is infiltrated by somatosensory input in lieu of the visual input. Interestingly, the input is specific for "discrimination of meaningful geometric forms such as Braille. ${ }^{53, "}$ It has also been shown that cells located in the (lateral suprasylvian gyrus), which do not respond to visual stimuli in health, are active when the occipital cortex is damaged. ${ }^{52}$ Additionally, research on lab animals has shown that visual function can be recovered even in the presence of a bilateral visual cortex lesion. ${ }^{50}$ The fourth type of neuroplasticity described is map expansion. This occurs as a specific activity is repeated over time or exposure to a stimulus is experienced in repetition. A useful illustration is the enlarged somatosensory map for the left hand of an experienced violinist. Repeated activity over time to the same cortical area resulted in a greater representation of left hand relative to the right hand. ${ }^{53}$ 
Brain injury has a relatively common incidence in the United States and is often associated with visual deficits, including binocular dysfunction. Contemporary models of neuroplasticity provide a picture of the human brain as an organ that has the ability to regenerate and reorganize. When damaged, the brain seems to be amenable to therapeutic measures, such as vision therapy. Vision therapy has been widely prescribed to treat brain injury induced binocular dysfunction. The literature contains several retrospective reviews of vision therapy for brain injury, but no studies have been prospective in design. The aim of this study was to evaluate the effectiveness of home-based computer vision therapy for treatment of binocular vision disorders in adults with a history of brain injury. 


\section{METHODS}

\section{$\underline{\text { Subjects }}$}

The Ohio State University Institutional Review Board (IRB) reviewed and approved the study protocol, informed consent document, Health Insurance Portability and Accountability Act (HIPAA) form, data collection form, and study brochure. Written informed consent was obtained from each potential subject prior to the eligibility examination. The tenets of the Declaration of Helsinki were followed throughout the study.

\section{Study Aims}

The goal of this study was to determine whether home based computer vision therapy/orthoptics is effective in improving signs and symptoms of binocular dysfunction (convergence insufficiency, accommodative insufficiency, and fusional vergence dysfunction) secondary to brain injury.

$\underline{\text { Inclusion and Exclusion Criteria }}$

Subjects between the ages of 18 and 85 with a history of brain injury at least three months prior were recruited. Brain injury was defined as an insult to the brain caused by 
an external physical force, cerebrovascular accident, or toxin (i.e. not of degenerative or congenital nature). Inclusion criteria also included at least $20 / 25$ best corrected visual acuity at distance (20 feet equivalent) and near ( 40 centimeters) and the presence of convergence insufficiency, fusional vergence dysfunction, and/or accommodative insufficiency. Convergence insufficiency was defined as a condition consisting of exophoria at near $\geq 4 \triangle$ greater than the phoria at distance, receded near point of convergence of $\geq 6 \mathrm{~cm}$ break, and insufficient PFV (i.e., failing Sheard's criterion or minimum normative PFV of $15 \triangle$ base-out to blur, or break if no blur finding). Fusional vergence dysfunction was defined as a condition consisting of insufficient PFV (i.e., failing Sheard's criterion or minimum normative PFV of less than $15 \triangle$ base-out blur or break if no blur finding), insufficient NFV (less than $12 \triangle$ base-in to blur or break), or insufficient vergence facility $(<15$ cycles per minute using a $12 \triangle$ base-out $/ 3 \triangle$ base-in split prism). For non-presbyopic subjects, accommodative insufficiency was defined as having amplitude of accommodation 2 or more diopters (D) below the minimum expected for the subject's age using the formula $15 \mathrm{D}-0.25$ (age in years).

Additional inclusion criteria included having an eye exam with refraction in the last three months, presence of 500" random dot stereopsis on Randot stereoacuity testing, willingness to wear glasses or contact lenses to correct refractive error if necessary, and willingness to discontinue wearing a plus-add bifocal (pre-presbyopes only, if applicable). Access to a personal computer with an internet connection was required to enable monitoring of therapy activity via a secure database. No minimum (Convergence Insufficiency Symptom Survey (CISS) score was required for eligibility in order to allow subjects with low CISS scores due to avoidance of near work to participate in the study. 
Exclusion criteria included constant strabismus, pregnancy, history of neurological disease (e.g. MS, Parkinson's), and developmental disability, mental retardation, or learning disability that may interfere with performing therapy (at investigator discretion).

\section{$\underline{\text { Recruitment of Subjects }}$}

A study brochure outlining the purpose of the study, mode of therapy, the eligible age range, the risks of treatment, responsibilities of participants, directions to the College of Optometry, and investigator contact information was distributed among the College of Optometry clinical services, Dodd Hall rehabilitation clinic, and to various community practitioners who see TBI patients (both optometrists and non-optometrists including neuropsychologists and rehabilitative medicine physicians).

\section{$\underline{\text { Testing Procedures }}$}

Subject history collected included date of birth, date of brain injury, and type of brain injury. Prior spectacle correction was checked by lensometry. Mode of near correction (e.g. single vision glasses, lined bifocals, progressive addition lenses) for presbyopes was assessed as it would impact the proper correction to wear during computer therapy tasks.

The Convergence Insufficiency Symptom Survey ${ }^{56}$ (CISS) (Appendix A) was administered to all subjects prior to performing any other testing and again at the end of the eligibility testing according to the procedure detailed in the CITT. ${ }^{29}$ Before administering the survey, the subject was given a card with printed response options. The 
subject was instructed as follows, "Please answer the following questions about how your eyes feel when reading or doing close work. If you have the problem, please tell me whether the problem occurs - Never, Infrequently (not very often), Sometimes, Fairly often, or Always". The questions were read exactly as written. If the subject responded with "yes," the subject was asked to qualify the frequency of occurrence with "Never, Infrequently (not very often), Sometimes, Fairly often, or Always". The response to each question was recorded on the CISS form and responses were scored as zero points for "Never," one point for "Infrequently," two points for "Sometimes," three points for "Fairly Often," and four points for "Always." The minimum score was zero and the maximum score was sixty.

Best corrected visual acuity was measured using the rear-illuminated Snellen project-o-chart at distance and a Snellen equivalent near acuity card at $40 \mathrm{~cm}$. Manifest subjective refraction was performed if the subject's visual acuity at distance or near was less than 20/25. Refraction was performed according to standard practice. Versions were tested using a penlight to check for comitancy of extraocular muscle movements and to rule out any underactions or overactions. Pupil size and reflexes were assessed using a penlight. Any previously undiagnosed anomalies were to be referred for neurological evaluation. All testing was performed with the subject wearing appropriate correction. The Randot Stereotest (Stereo Optical, Chicago, IL - Figure 1) was used for assessing stereopsis. The test booklet was held at $40 \mathrm{~cm}$ and the subject was asked to wear polarized glasses. The plane of the booklet was held parallel to the subject's face. Global stereopsis was assessed using the random dot targets on the right hand side of the booklet. The subject was asked to view the lower set of four boxes (250") and to report 
what was seen in each. The subject was required to appropriately identify the shape in each box to receive credit. If the subject correctly identified each box correctly, then global stereopsis was recorded as 250 ". If the subject did not achieve 250 " he/she was then asked to look at the top four boxes (500”). If these targets were correctly identified, then it was recorded that the subject achieved 500" of global stereopsis. If these targets were not identifiable, then it was recorded that the subject did not have measurable random dot stereopsis with the Randot. Local stereopsis was also assessed using the ten sets of three circles on the left side of the booklet. The subject's last correctly identified set was recorded as the degree of local stereopsis.

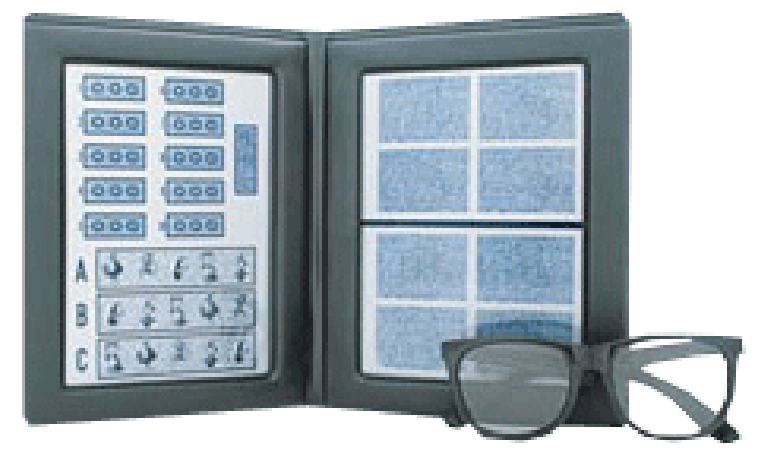

Figure 1. Randot Stereo Test Booklet with Polarized Glasses Photo courtesy of www.stereooptical.com

The cover test was performed with a 20/30 letter isolated at distance. The subject was asked to fixate the letter and keep it clear for the duration of the test. The unilateral cover test was performed first. The subject's left eye was covered for about three seconds while the right eye was watched for movement on the cover stroke. This was repeated two more times. The same steps were then repeated while observing the left eye. It was noted whether strabismus was present or absent. If strabismus was present, it 
was noted whether the strabismus was constant or intermittent and unilateral or alternating. Alternate cover testing was performed next to assess the presence and magnitude of any deviation. The time of cover over each eye lasted at least one second. The deviation was neutralized with a bar prism or loose prisms. Increasing amounts of prism were added until reversal of the deviation was noted five consecutive times on the alternating strokes of the cover test. The greatest amount of prism that showed neutral movement was recorded as the magnitude of the phoria or strabismus. During the cover test, the investigator paid close attention to whether a vertical deviation was present. If one was observed, then the deviation was neutralized along with the lateral deviation using multiple loose prisms. Cover testing was repeated at $40 \mathrm{~cm}$ using a single isolated 20/30 Snellen equivalent letter on the Gulden hand held fixation stick (Gulden Fixation Stick \#15302, Figure 2). The subject was instructed to keep the target clear during the test and to keep looking directly at the target. The presence and magnitude of any tropia or phoria was then recorded on the exam form. 


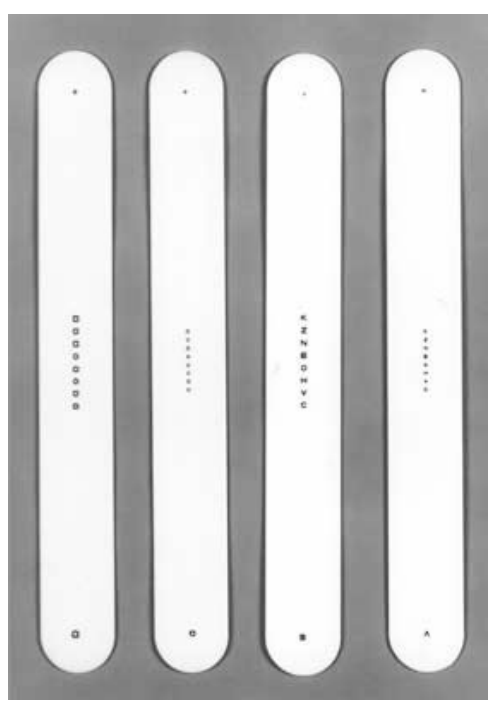

Figure 2. Fixation Sticks

Photo courtesy of www.guldenophthalmics.com

The near point of convergence (NPC) was assessed using the Astron International (ACR/21) Accommodative Rule, a rod with a moveable target and metric markings according to the procedure detailed in the CITT $^{29}$ (Figure 3). A single column of letters of 20/30 Snellen equivalent at $40 \mathrm{~cm}$ was used as the target. The center of the forehead at the level of the brow was used as the zero measure point from which the NPC was taken. The target was moved toward the subject at approximately one to two centimeters per second. The target was moved towards the subject until the subject reported double vision or the examiner observed an objective loss of fusion. This was considered the NPC break. The target was then moved away from the subject until the subject reported single vision or the examiner observed a recovery of fusion. This was considered the NPC recovery. The NPC break and recovery were measured to the nearest half centimeter. These measurements were taken three times with a 30 second break in between and recorded as the NPC break and recovery on the examination form. The mean NPC break and recovery values were used for analysis. 


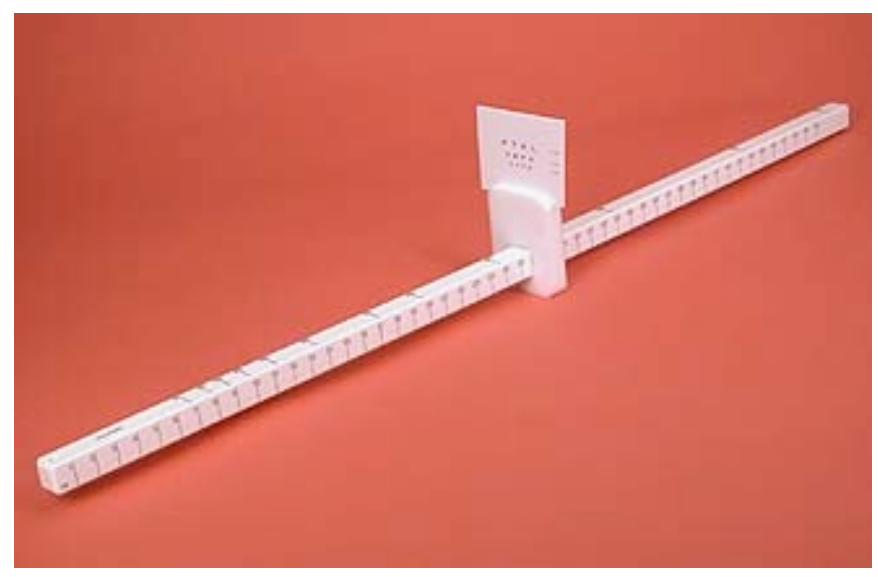

Figure 3. Astron International (ACR/21) Accommodative Rule Photo courtesy of $w w w . g u l d e n o p h t h a l m i c s . c o m$

Negative fusional vergence (NFV) ranges were measured with a horizontal prism bar (Gulden B-16 horizontal prism bar levels from $1 \triangle$ to $45 \triangle$ - Figure 4 ) and a hand-held fixation target (Gulden Fixation Stick \#15302) with a single column of letters of 20/30 Snellen equivalent according to the procedure detailed in the CITT. The target was held by the subject at a distance of $40 \mathrm{~cm}$. The subject was instructed to try and keep the target single as long as possible as prism was introduced before the eye. The procedure was begun by holding the prism bar in a base-in direction in front of the right eye starting at $1 \triangle$. The amount of base-in prism was increased in front of the right eye at approximately $2 \Delta$ per second. The subject was asked to state when he experienced blurred or double vision or noted any lateral movement of the target. If blur was reported, this was recorded as the blur value and the subject was asked to report when the target split into two or became double. If the target became double, the subject was asked to report if it stayed two or came back into one. When the subject could no longer keep it single, this value was recorded as the base-in break. If loss of fusion was observed, the magnitude of prism at which loss of fusion occurred was recorded as the break value. The 
base-in demand was increased by 5 more prism diopters and then at a rate of about $2 \Delta$ per second, the base-in prism was reduced until the subject regained single vision. This was recorded as the base-in recovery value. The blur, break and recovery findings were recorded. This measurement was taken three times, with a thirty second break in between, and the mean of each was used for analysis.

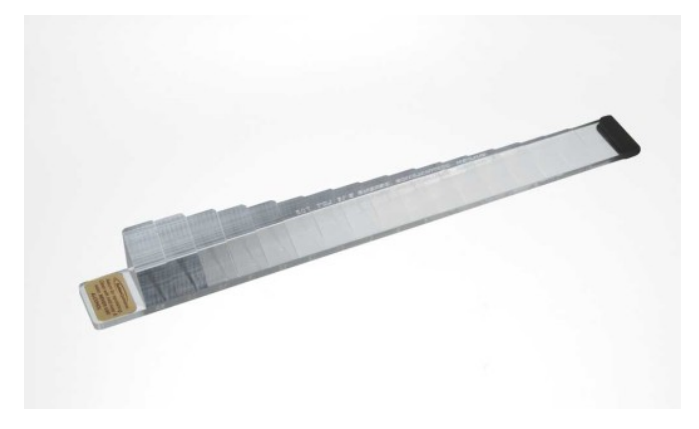

Figure 4. Prism Bar

Photo courtesy of www.guldenophthalmics.com

Positive fusional vergence (PFV) ranges were measured using a horizontal prism bar (Gulden B-15 horizontal prism bar levels from $1 \triangle$ to $45 \triangle$ ) and a hand-held fixation target (Gulden Fixation Stick \#15302) with a single column of letters of 20/30 Snellen equivalent according to the procedure detailed in the CITT. The target was held by the subject at a distance of $40 \mathrm{~cm}$. The subject was instructed to try and keep the target single as long as possible as prism was introduced before the eye. The procedure was begun by holding the prism bar in a base-out direction in front of the right eye. The amount of base-out prism was increased in front of the right eye at approximately $2 \Delta$ per second. The subject was asked to state when he experienced blurred or double vision or saw lateral movement of the target. When the target was reported to be single and blurry, this was recorded as the base-out to blur finding and the subject was asked to report when the 
target split into two as the amount of prism was increased further. When the target was reported to double, the subject was asked if the letters became one or stayed two. When the subject could no longer keep it single, this value was recorded as the base-out to break finding. If loss of fusion was observed, the magnitude of prism at which loss of fusion occurred was recorded as the break value. The amount of base-out demand was increased by 5 more prism diopters and then at a rate of about $2 \Delta$ per second, the base-out prism was reduced until the subject regained single vision. This was recorded as the baseout recovery value. Positive fusional vergences were measured three times, with thirty seconds in between each measurement, and the mean value for each finding was used for analysis.

Vergence facility was assessed using a target with a vertical row of 20/30 Snellen equivalent letters at a test distance of $40 \mathrm{~cm}$ on a hand-held fixation stick (Gulden Fixation Stick \#15302, Gulden Ophthalmics, Elkins Park, PA). A 12 $\Delta$ BO/3 $\Delta$ BI split prism was used for this procedure (Figure 5). The subject was instructed to look at the vertical column of letters as the prism was placed in front of his/her eye and to report when the target became clear and single by saying the word "single." The task was demonstrated to the subject and the subject was informed that the test would continue for sixty seconds. Beginning with the BI prism, the prism was introduced in front of the subject's right eye and timed using a hand held digital stopwatch. Each time the subject reported the target as single, the investigator moved the split prism to introduce the opposite prism. Fusing both the $3 \Delta \mathrm{BI}$ prism and the $12 \Delta \mathrm{BO}$ prism once counted as one cycle. Vergence facility was recorded in cycles per minute to the closest half cycle. 


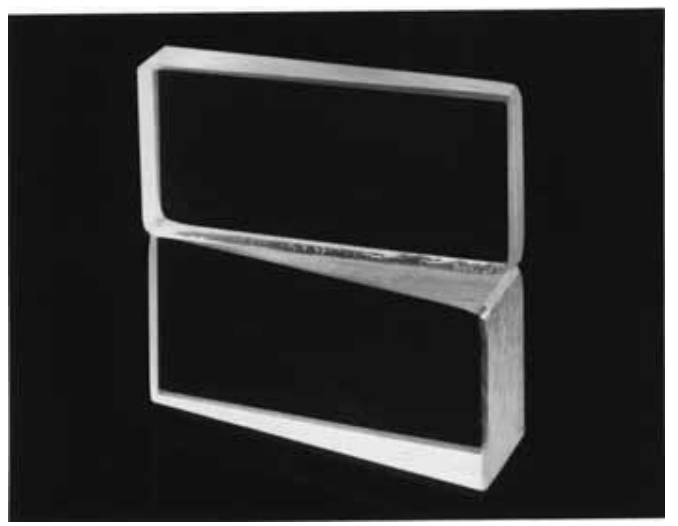

Figure 5. $12 \Delta \mathrm{BO} / 3 \Delta \mathrm{BI}$ Vergence Facility Prism Photo courtesy of www.guldenophthalmics.com

For nonpresbyopes, accommodative testing also was performed. Monocular amplitudes of accommodation were measured according to the procedure detailed in the CITT. The subject's left eye was occluded. Ambient overhead lighting provided good illumination. The Astron International (ACR/21) Accommodative Rule (Gulden Ophthalmics, Elkins Park, PA) was used for testing and a single column of letters of 20/30 Snellen equivalent at $40 \mathrm{~cm}$ was used as the target. The forehead just above the level of the brow of the eye being tested was used as the zero measure point from which the accommodative amplitude measure was taken. The accommodative rule was held gently against the subject's forehead and the target was moved toward the subject at approximately 1 to $2 \mathrm{~cm} / \mathrm{s}$. The subject was instructed to report immediately when the target first started to become blurry. At this point, the target was stopped and the subject was asked if the letters became clear or remained blurred. If the letters cleared, the target was moved closer to the subject at the same rate until blur was reported again. The point of first sustained blur was considered to be the endpoint. The accommodative amplitude was recorded to the nearest half centimeter on the exam form and subsequently converted 
into a dioptric value. The right eye was occluded and the procedure was repeated for the left eye.

Monocular accommodative facility also was assessed according to the procedure detailed in the CITT. The target for this test was the vertical row of 20/30 Snellen equivalent letters on a hand held fixation stick (Gulden Fixation Stick \#15302) held at 40 $\mathrm{cm}$. The lenses used were $+/-2.00 \mathrm{D}$ lens flippers (Figure 6). The subject was instructed to focus on the vertical row of letters and attempt to make them clear each time a new lens was introduced in front of the eye and to report when the letters were clear by saying "clear." The subject also was told not to be concerned with size differences between the two lenses, but to focus on clarity. The subject's left eye was occluded. The investigator began by introducing the $+2.00 \mathrm{D}$ lens in front of the subject's right eye and switched to the $-2.00 \mathrm{D}$ lens as soon as the subject reported the target being clear. Clearing the letters through both the $+2.00 \mathrm{D}$ and $-2.00 \mathrm{D}$ lenses counted as one cycle. One cycle was completed for purposes of demonstration before testing began. Testing was timed for sixty seconds and monocular accommodative facility in cycles per minute was recorded to the nearest half cycle. The procedure was repeated for the left eye with the right eye occluded. 


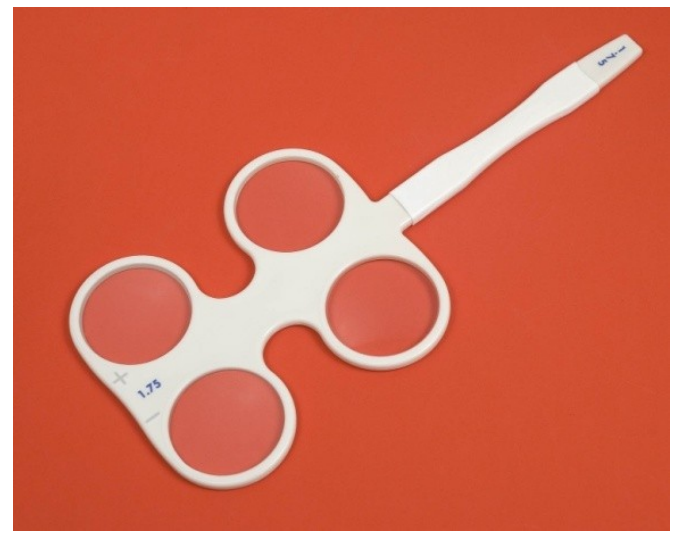

Figure 6. Lens Flippers

Photo courtesy of www.guldenophthalmics.com

\section{Therapy Procedures}

The HTS computer software was demonstrated and provided to all eligible subjects (Figure 7). The red and blue glasses that accompany the software were shown and the subject was instructed that the glasses must be worn for all therapy tasks. Using the "Demo" feature on HTS, "base-in vergence" demonstrated to the subject. On presentation of the first screen, the investigator asked the question, "What do you see on the screen?" An open ended question such as this was asked to assure that the subject appreciated the random dot stereogram of the square using stereopsis. The subject was then asked, "Where do you see the box popping out of the screen relative to the letter in the center?" If the subject responded correctly, the subject was asked to press the corresponding arrow on the computer keyboard. If the target was seen above the center letter, then the "up" arrow needed to be pressed. If the target was seen to the right of the center letter, then the "right" arrow needed to be pressed, and so on. The subject was told that if more than ten seconds elapsed before responding to a presentation, then the system would present a new target location. Also, if the target was not seen, the subject was 
instructed to press the space bar to alert the therapy system. After performing several presentations correctly, the investigator asked the subject to remove the red-blue glasses and to look at the separation of the red and blue images on the computer screen. A brief explanation was given to show the subject that the system was increasing the demand for the eyes to turn and that the software would calculate how much the subject achieved in any given therapy session. This provided an opportunity to explain the investigator's control program and its ability to monitor the subject's progress via HTS' secure online database. The security aspect of this feature was emphasized. The base-out and autoslide vergence procedures also were demonstrated. The subject was informed that during later phases of the therapy, the software would require the eyes to both turn in and turn out during the same session. If applicable, the accommodative portion of HTS also was demonstrated. Saccades, pursuits, and vertical fusion were not tested during the baseline and outcome examinations and therefore, these procedures were not performed. The subject was also informed that the investigator would set the proper tasks and duration of therapy via the control program and that the therapy session would run automatically. The subject was informed that 12 weeks would be the target amount of time to be enrolled in the study with the option of adding an additional 4 weeks if necessary for a maximum total of 16 weeks. Subjects who progressed sufficiently with the HTS program also were to be offered the PTS II therapy program. The subject was instructed to choose a convenient time in the next day or two to install the program and run a first session. 


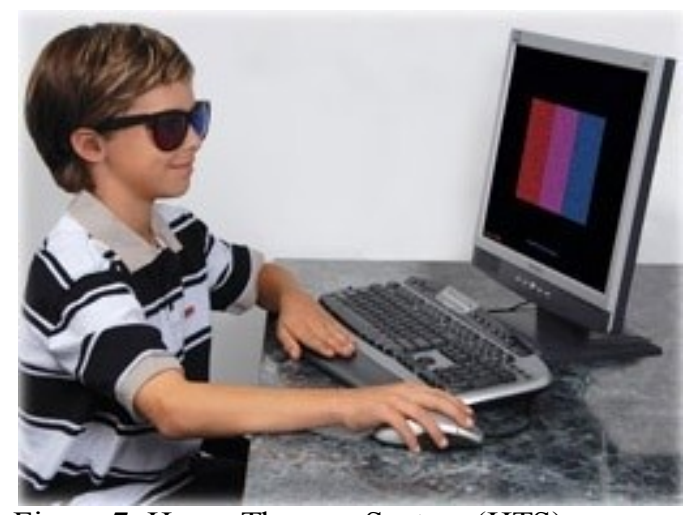

Figure 7. Home Therapy System (HTS)

Photo courtesy of www.hometherapysystem.com

\section{Follow-Up Visits}

Follow-up visits were scheduled every four weeks throughout the subject's enrollment in the study. The tests performed at each follow-up visit were CISS, visual acuity, cover test, NPC, NFV, PFV, vergence facility, accommodative amplitudes (if applicable), and accommodative facility (if applicable). At each visit, an update on progress both from the computer software report and from the clinically measured data was presented to the subject and any questions or concerns were addressed.

Progress in between follow-up visits was monitored via the computer software report. This provided a record of date and time of each therapy session completed, amount of time spent on therapy, and level achieved for a given task. The subjects also were contacted via phone and email in between follow-up visits to address questions or concerns and to encourage consistency of performing therapy.

No computer based therapy was performed in office at any follow up visit. 


\section{Compliance}

At the baseline visit, each subject was informed that the five therapy sessions should be completed each week for 12-16 weeks. To emphasize this point, each subject was instructed that every time seven days passed, five therapy sessions should have been completed. Compliance was encouraged throughout the study. Phone calls were made and emails were exchanged in between follow up visits to keep the patient mindful of the 5 session per week prescribed and to answer any questions or concerns. Number of sessions completed and level achieved in the HTS program (BI/BO vergence, Autoslide, Jump Ductions, or program completed) were recorded as indicators of compliance.

If the subject had not completed the HTS program at the time of the 12 week follow up visit, the subject was given the option to continue the program for 4 more weeks.

\section{Classification of Successful or Improved}

Subjects were classified as "successful" or "improved" based upon the criteria used in the Convergence Insufficiency Treatment Trial (CITT) and normative values. ${ }^{29,67}$

Specifically, subjects were classified as "successful" on each outcome measure according to the following criteria: CISS score less than 21, NPC less than $6 \mathrm{~cm}$, normal PFV (i.e., greater than $15 \Delta$ and passing Sheard's criterion), normal NFV (12 $\Delta$ or greater), normal vergence facility (15 cycles per minute), and accommodative amplitude at or above expected value according to Hofstetter's formula (non-presbyopic subjects only). A score of 21 on the CISS was chosen as a cut-off in light of the CITT study which showed a score of 21 to discriminate between adults (ages 19 to 30) with symptomatic convergence 
insufficiency versus normal binocular vision. ${ }^{56}$ Similarly, a subject was classified as "successful" or "improved" for an outcome measure based upon the following criteria:

CISS score less than 21 or a decrease in CISS score of 10 or more points, NPC less than 6 $\mathrm{cm}$ or a decrease in NPC of more than $4 \mathrm{~cm}$, normal PFV (i.e., greater than $15 \Delta$ and passing Sheard's criterion) or an increase in PFV of $10 \Delta$ or more, normal NFV ( $12 \Delta$ or greater) or an increase of $6 \Delta$ or greater, normal vergence facility (15 cycles per minute) or an increase of 3 cycles per minute or more or an increase in accommodative amplitude to minimum expected value for age, if applicable (non-presbyopic subjects only).

\section{$\underline{\text { Statistical Analysis }}$}

This study was designed as a pilot study with a goal of collecting baseline data to estimate the need for and sample size of a larger clinical trial. All data analyses were performed using the SPSS 17.0 software (IBM Corporation, Somers, NY). A one group by three time period repeated measures analysis of variance (ANOVA) was used to detect change in clinical measures between study visits. Tukey adjusted p-values were used due to small sample size. NFV, PFV, NPC, total fusional vergence, vergence facility, and CISS scores were treated as continuous variables. Unless specifically stated otherwise, an $\alpha$-level of 0.05 was used. Percentage of subjects classified as successful or improved was determined for each clinical measure and for a composite which included both PFV and NPC. 


\section{$\underline{\text { RESULTS }}$}

\section{$\underline{\text { General Information }}$}

Enrollment began in August 2009 and was completed in June 2010. Therapy sessions were completed in August 2010. Nineteen subjects enrolled in the study with 13 of these completing the study. Three subjects missed the 4 week follow up, five missed the 8 week follow up, and six missed the 12 week follow up. Two subjects had not completed the HTS program at the time of the 12 week follow up visit and chose the option to complete 16 weeks of therapy.

\section{$\underline{\text { Patient Demographics }}$}

The mean age of the group was 45.2 years $(+/-12.5)$. Fifteen of the 19 subjects suffered from a mechanical TBI, with the most common context being automobile related accidents $(\mathrm{n}=10)$. Three of the remaining subjects suffered from cerebrovascular accidents (CVA) and the other one suffered from organic brain syndrome via a venomous snake bite. The mean amount of time passed from date of injury to date of baseline study visit was 2.2 years (excluding two outlying values that were 14 and 15.5 years since injury, respectively.) Twelve were male and 7 were female. Sixteen subjects were Caucasian, 2 were African American and 1 was of Middle Eastern descent. One subject presented wearing spectacles which included $4 \Delta$ base-in prism. The patient was unable to 
see single without the glasses and was allowed to continue wearing these spectacles during therapy and testing. Values for clinical measures were adjusted accordingly when entered into the data set. No subjects were excluded due to inability to understand therapy and requirements for completion of therapy. No subjects were referred for neurological workup due to previously undetected anomalies.

Each subject was asked to report the type of brain injury that he/she sustained to the extent that knowledge of the event allowed. Table 1 summarizes the information offered by each subject. 
Table 1. Type of Brain Injury

\begin{tabular}{|c|c|l|}
\hline Subject & Type & Notes \\
\hline 1 & TBI & bicycling accident; skull fractures, left side subdural hematomas \\
\hline 2 & CVA & hemorrhagic; right side frontal and parietal lobe \\
\hline 3 & TBI & motorcycle accident \\
\hline 4 & TBI & bicycling accident, hit by car; subdural hematoma \\
\hline 5 & TBI & car accident; was in coma for 5 weeks \\
\hline 6 & CVA & ischemic; right internal carotid \\
\hline 7 & CVA & hemorrhagic; left side aneurysm \\
\hline 8 & TBI & car accident \\
\hline 9 & TBI & car accident; left side impact \\
\hline 10 & ABI & cobra snake bite; organic brain syndrome \\
\hline 11 & TBI & cabinets fell on head \\
\hline 12 & TBI & car accident \\
\hline 13 & TBI & car accident; subarachnoid hemorrhage \\
\hline 14 & TBI & fell from 15 feet, landed on back of head; spent 5 months in hospital \\
\hline 15 & TBI & tree limb; frontal impact \\
\hline 16 & TBI & motorcycle accident \\
\hline 19 & TBI & fell backwards on ice; concussion \\
\hline 18 & TBI & car accident; frontal impact \\
\hline $13 I$ & car accident; whiplash \\
\hline 19 & \\
\hline 19 &
\end{tabular}

\section{$\underline{\text { Baseline Clinical Profile }}$}

The baseline clinical characteristics of the group of 19 subjects included a mean cover test value of orthophoria $(+/-1.05 \Delta$, range $=2 \Delta$ exophoria $-4 \Delta$ esophoria $)$ at distance and $7.16 \Delta$ exophoria $(+/-5.05 \Delta$, range $=14 \Delta$ exophoria $-8 \Delta$ esophoria $)$ at $40 \mathrm{~cm}$. The mean NFV value at $40 \mathrm{~cm}$ was $12.32 \Delta(+/-4.25 \Delta$, range $=4.67 \Delta-20.00 \Delta)$ to blur or break if 
no blur and $10.21 \Delta(+/-4.15 \Delta$, range $=2.33 \Delta-16.67 \Delta)$ to recovery. The mean PFV value at $40 \mathrm{~cm}$ was $8.42 \Delta(+/-5.77 \Delta$, range $=1.00 \Delta-25.00 \Delta)$ to blur or break if no blur and $8.21 \Delta(+/-6.07 \Delta$, range $=-2.00 \Delta-23.33 \Delta)$ to recovery. The mean NPC break was 17.48 $\mathrm{cm}(+/-10.42 \mathrm{~cm}$, range $=5.83 \mathrm{~cm}-43.67 \mathrm{~cm})$ and recovery was $21.77 \mathrm{~cm}(+/-11.40 \mathrm{~cm}$, range $=7.00 \mathrm{~cm}-49.00 \mathrm{~cm})$. The mean vergence facility $(12 \Delta \mathrm{BO} / 3 \Delta \mathrm{BI})$ value at $40 \mathrm{~cm}$ was 3.87 cycles per minute $(+/-4.36$, range $=0 \mathrm{cpm}-14 \mathrm{cpm})$. The mean CISS score at baseline was $32.01(+/-13.16$, range $=10-50.5)$ out of a maximum score of 60 . The most commonly reported symptoms were slow reading, difficulty concentrating while reading, having to re-read lines of text, trouble remembering what was read, and frequent loss of place.

The baseline clinical profile of the group that completed at least 12 weeks of therapy $(n=13)$ is compared to the group that was lost to follow up $(n=6)$ in table 2 . By direct comparison, those who completed the study had more severe signs of binocular dysfunction, were more symptomatic, had a longer time since brain injury, and were slightly younger than those who were lost to follow up. 
Table 2. Clinical Measures - Completed versus Lost to Follow Up

\begin{tabular}{|c|c|c|}
\hline & $\begin{array}{c}\text { Completed } \\
(\mathbf{n = 1 3})\end{array}$ & $\begin{array}{c}\text { Lost to } \\
\text { follow up } \\
(\mathbf{n}=\mathbf{6})\end{array}$ \\
\hline Age (yrs) & 42.3 & 46.5 \\
\hline Time Since $(\mathrm{yrs})$ & 4.2 & 3.4 \\
\hline Near Phoria $(\Delta)$ & 9.3 exo & 5.5 exo \\
\hline NFV $(\Delta)$ & 13.3 & 11.8 \\
\hline PFV $(\Delta)$ & 5.4 & 9.8 \\
\hline NPC Break $(\mathrm{cm})$ & 21.0 & 15.9 \\
\hline VF (cpm) & 2.9 & 4.3 \\
\hline CISS & 39.3 & 28.6 \\
\hline
\end{tabular}

\section{Clinical Profile Post Vision Therapy}

The clinical characteristics of the group of 13 subjects after vision therapy included a mean cover test value of orthophoria $(+/-0.95 \Delta$, range $=2 \Delta$ exophoria $-2 \Delta$ esophoria $)$ at distance and $6.29 \Delta$ exophoria $(+/-6.70 \Delta$, range $=16 \Delta$ exophoria $-8 \Delta$ esophoria $)$ at $40 \mathrm{~cm}$. The mean NFV value at $40 \mathrm{~cm}$ was $16.68 \Delta(+/-6.56 \Delta$, range $=6.00 \Delta-30.00 \Delta)$ to blur and $13.81 \Delta(+/-5.56 \Delta$, range $=5.33 \Delta-25.00 \Delta)$ to recovery. The mean PFV value at 40 cm was $20.43 \Delta(+/-9.94 \Delta$, range $=4.00 \Delta-35.00 \Delta)$ to blur (or break if no blur) and $17.81 \Delta(+/-8.98 \Delta$, range $=0.33 \Delta-30.00 \Delta)$ to recovery. The mean NPC break was 10.1 $\mathrm{cm}(+/-8.6 \mathrm{~cm}$, range $=3.67 \mathrm{~cm}-31.67 \mathrm{~cm})$ and recovery was $13.69 \mathrm{~cm}(+/-8.73 \mathrm{~cm}$, 
range $=6.00 \mathrm{~cm}-34.33 \mathrm{~cm})$. The mean vergence facility $(12 \Delta \mathrm{BO} / 3 \Delta \mathrm{BI})$ value at $40 \mathrm{~cm}$ was 13.5 cycles per minute $(+/-6.79$, range $=0.5 \mathrm{cpm}-20.0 \mathrm{cpm})$. The mean CISS score after vision therapy was $21.29(+/-13.93$, range $=3.5-45.5)$ out of a maximum score of 60. Table 3 provides clinical measures for each individual subject at baseline and at the outcome visit. 
Table 3. Baseline and Outcome Visit Values

\begin{tabular}{|c|c|c|c|c|c|c|c|c|}
\hline \multirow[b]{2}{*}{ Patient } & \multirow[b]{2}{*}{$\begin{array}{c}\text { Phoria } \\
\text { ( } \Delta \text { dist } / \text { near) }\end{array}$} & \multicolumn{5}{|c|}{ Baseline } & & \\
\hline & & $\begin{array}{l}\text { NFV } \\
40 \mathrm{~cm}\end{array}$ & $\begin{array}{l}\text { PFV } \\
40 \mathrm{~cm}\end{array}$ & $\begin{array}{c}\text { NPC } \\
\text { (cm brk/rec) }\end{array}$ & $\begin{array}{c}\text { VF } \\
(\mathbf{c p m})\end{array}$ & $\begin{array}{l}\text { CISS } \\
\text { score }\end{array}$ & & \\
\hline 1 & 0/8XP & $\mathrm{x} / 15 / 13$ & $\mathrm{x} / 11 / 8$ & $7 / 10$ & 0 & 23.5 & & \\
\hline 2 & 0/8XP & $\mathrm{x} / 12 / 9$ & $\mathrm{x} / 14 / 12$ & $31 / 33$ & 10 & 24 & & \\
\hline 3 & $4 \mathrm{EP} / 8 \mathrm{EP}$ & $\mathrm{x} / 5 / 2$ & $10 / 14 / 12$ & $30 / 37$ & 6 & 23.5 & & \\
\hline 4 & 0/8XP & $\mathrm{x} / 17 / 14$ & $12 / 16 / 13$ & $8 / 10$ & 10 & 20 & & \\
\hline 5 & $0 / 6 \mathrm{XP}$ & $\mathrm{x} / 15 / 12$ & $3 / 7 / 5$ & $6 / 9$ & 3 & 14 & & \\
\hline 6 & $0 / 12 X P$ & $\mathrm{x} / 19 / 17$ & $4 / 5 / 3$ & $12 / 15$ & 3 & 10 & & \\
\hline 7 & 0/8XP & $\mathrm{x} / 11 / 8$ & $6 / 8 / 5$ & $24 / 30$ & 0 & 50 & & \\
\hline 8 & 0/4EP & $\mathrm{x} / 12 / 10$ & $25 / 28 / 23$ & $19 / 32$ & 14 & 20.5 & & \\
\hline 9 & $0 / 10 X P$ & $\mathrm{x} / 16 / 13$ & $12 / 18 / 15$ & $11 / 16$ & 3 & 46.5 & & \\
\hline 10 & $0 / 12 X P$ & $9 / 16 / 13$ & $11 / 19 / 11$ & $9 / 13$ & 5.5 & 38 & & \\
\hline 11 & 0/4XP & $\mathrm{x} / 10 / 6$ & $9 / 15 / 11$ & $6 / 7$ & 6 & 31 & & \\
\hline 12 & $2 \mathrm{XP} / 12 \mathrm{XP}$ & $\mathrm{x} / 20 / 16$ & $\mathrm{x} / 3 / 1$ & $44 / 49$ & 0 & 30 & & \\
\hline 13 & 0/14XP & $\mathrm{x} / 17 / 15$ & $8 / 14 / 10$ & $13 / 16$ & 10 & 45 & & \\
\hline 14 & 0/6XP & $9 / 11 / 7$ & $2 / 6 / 4$ & $22 / 27$ & 0.5 & 50.5 & & \\
\hline 15 & 0/6XP & $\mathrm{x} / 9 / 4$ & $\mathrm{x} / 6 / 3$ & $14 / 18$ & 0.5 & 22 & & \\
\hline 16 & $0 / 12 X P$ & $\mathrm{x} / 12 / 9$ & $\mathrm{x} / 9 / 7$ & $16 / 21$ & 0.5 & 31 & & \\
\hline 17 & $0 / 0$ & $7 / 10 / 7$ & $\mathrm{x} / 12 / 11$ & $9 / 13$ & 0.5 & 33 & & \\
\hline 18 & $0 / 6 \mathrm{XP}$ & $\mathrm{x} / 7 / 5$ & $\mathrm{x} / 1 /-2$ & $27 / 30$ & 0.5 & 46.5 & & \\
\hline 19 & 0/8XP & $12 / 15 / 13$ & $2 / 4 / 2$ & $25 / 27$ & 0.5 & 48 & & \\
\hline \multirow[b]{2}{*}{ Patient } & \multicolumn{8}{|c|}{ Post-Vision Therapy } \\
\hline & $\begin{array}{c}\text { Phoria } \\
(\Delta \text { dist/near })\end{array}$ & $\begin{array}{l}\text { NFV } \\
40 \mathrm{~cm}\end{array}$ & $\begin{array}{l}\text { PFV } \\
40 \mathrm{~cm}\end{array}$ & $\begin{array}{c}\text { NPC } \\
\text { (cm brk/rec) }\end{array}$ & $\begin{array}{c}\text { VF } \\
\text { (cpm) }\end{array}$ & $\begin{array}{l}\text { CISS } \\
\text { score }\end{array}$ & $\begin{array}{c}\text { Sessions } \\
\text { Completed }\end{array}$ & $\begin{array}{c}\text { Level } \\
\text { Reached }\end{array}$ \\
\hline 1 & 0/8XP & $\mathrm{x} / 15 / 13$ & $\mathrm{x} / 20 / 15$ & $4 / 9$ & 20 & 26.5 & 61 & 2 \\
\hline 2 & $0 / 8 X P$ & $\mathrm{x} / 17 / 15$ & $\mathrm{x} / 24 / 20$ & $5 / 8$ & 15 & 16 & 57 & 3 \\
\hline 3 & $2 \mathrm{EP} / 6 \mathrm{EP}$ & $\mathrm{x} / 28 / 21$ & $\mathrm{x} / 32 / 25$ & $6 / 10$ & 18 & 9.5 & 71 & 3 \\
\hline 4 & $0 / 10 X P$ & $16 / 17 / 14$ & $\mathrm{x} / 25 / 20$ & $6 / 10$ & 20 & 4.5 & 22 & 3 \\
\hline 5 & $0 / 6 \mathrm{XP}$ & $\mathrm{x} / 13 / 11$ & $17 / 19 / 16$ & $7 / 11$ & 9 & 16.5 & 19 & 1 \\
\hline 6 & $2 \mathrm{XP} / 12 \mathrm{XP}$ & $\mathrm{x} / 23 / 15$ & $\mathrm{x} / 35 / 30$ & $4 / 7$ & 19 & 3.5 & 76 & 4 \\
\hline 7 & 0/8XP & $6 / 9 / 5$ & $4 / 8 / 5$ & $32 / 34$ & 0.5 & 45.5 & 40 & 1 \\
\hline 8 & $0 / 8 \mathrm{EP}$ & $\mathrm{x} / 11 / 8$ & $11 / 30 / 22$ & $16 / 21$ & 18.5 & 23 & 61 & 2 \\
\hline 9 & 0/8XP & $12 / 18 / 16$ & $14 / 20 / 17$ & $5 / 8$ & 18 & 34 & 47 & 3 \\
\hline 10 & $2 \mathrm{XP} / 16 \mathrm{XP}$ & $20 / 25 / 20$ & $28 / 37 / 27$ & $4 / 7$ & 15 & 14.5 & 55 & 4 \\
\hline 11 & - & - & - & - & - & - & 5 & 1 \\
\hline 12 & - & - & - & - & - & - & 0 & - \\
\hline 13 & - & - & - & - & - & - & 2 & 1 \\
\hline 14 & - & - & - & - & - & - & 6 & 1 \\
\hline 15 & 0/8XP & $\mathrm{x} / 30 / 25$ & $\mathrm{x} / 35 / 30$ & $4 / 6$ & 13 & 22 & 48 & 4 \\
\hline 16 & - & - & - & - & - & - & 30 & 1 \\
\hline 17 & $0 / 0$ & $8 / 13 / 9$ & $\mathrm{x} / 25 / 18$ & $9 / 12$ & 15.5 & 27 & 88 & 3 \\
\hline 18 & $0 / 6 \mathrm{XP}$ & $13 / 15 / 12$ & $\mathrm{x} / 10 / 8$ & $21 / 25$ & 6.5 & 43 & 54 & 3 \\
\hline 19 & - & - & - & - & - & - & 23 & 1 \\
\hline
\end{tabular}

Notes:

The column "Total Sessions" indicates the total number of therapy sessions completed. The "Level Reached" column indicates the highest level of the computer program that was attained by the subject. Level 1 stands for Base-In / Base-Out, Level 2 stands for Autoslide Vergence, Level 3 stands for Jump Ductions, and Level 4 stands for having completed the vergence portion of the program in its entirety. A "-" indicates that the subject was lost to follow up. 


\section{$\underline{\text { Analysis of Clinical Measures }}$}

One subject who did not complete any therapy was excluded from analysis. Each element of the clinical assessment was analyzed statistically for change across each point of data collection (e.g. baseline visit to week 12 visit). Because all subjects who completed therapy were presbyopic, accommodative function was not assessed. Significance is displayed as $\mathrm{p}$ values. Analysis of the cover test is shown in Table 4 below.

Table 4. Change in Phoria

\begin{tabular}{|c|c|c|c|c|c|}
\hline & Baseline & $\mathbf{4}$ weeks & $\mathbf{8}$ weeks & 12 weeks & Signif* \\
\hline & $\begin{array}{c}\text { Mean (SD) (pd) } \\
(\mathrm{N}=18)\end{array}$ & $\begin{array}{c}\text { Mean (SD) }(\mathrm{pd}) \\
(\mathrm{N}=16)\end{array}$ & $\begin{array}{c}\text { Mean (SD) (pd) } \\
(\mathrm{N}=14)\end{array}$ & $\begin{array}{c}\text { Mean (SD) (pd) } \\
(\mathrm{N}=13)\end{array}$ & \\
\hline Distance & 0.2 eso (0.9) & ortho (0.7) & ortho (0.8) & 0.2 exo (1.0) & 0.40 \\
\hline Near & 6.4 exo (5.6) & 7.1 exo (5.9) & 5.9 exo (6.4) & 5.8 exo (6.8) & 0.50 \\
\hline
\end{tabular}

*Repeated measures ANOVA comparing mean at weeks 0, 4, 8 and 12

Analysis of the distance and near cover tests revealed that the group's phoria did not change significantly from baseline to outcome at distance $(\mathrm{p}=0.40)$ or at near $(p=0.50)$. It was noted clinically on several subjects that the exophoria became more latent toward the later follow up visits, but still able to be broken down on the alternating cover test.

NFV was analyzed as the individual values for blur, break, and recovery (Table 5). Repeated measures ANOVA for NFV showed statistical significance for improvement (increase) in base-in to blur $(\mathrm{p}=0.037)$, break $(\mathrm{p}=0.003)$, and recovery $(\mathrm{p}=0.006)$ from baseline to outcome. Post hoc analysis using Tukey adjusted p values for base-in to blur 
showed a significant difference between baseline and week $12(\mathrm{p}=0.032)$, but not between any of the other visit to visit comparisons $(\mathrm{p} \geq 0.13)$. Post hoc analysis for base-in to break showed a significant difference between baseline and the week 4 visit $(\mathrm{p}=0.015)$ and between baseline and week $12(\mathrm{p}=0.004)$ but not between any of the other visit to visit comparisons $(\mathrm{p} \geq 0.27)$. Post hoc analysis for base-in to recovery showed a significant difference between baseline and week $4(\mathrm{p}=0.035)$ and between baseline and week 12 $(p=0.007)$, but not between any of the other visit to visit comparisons $(\mathrm{p} \geq 0.27)$.

Table 5. Change in Negative Fusional Vergence

\begin{tabular}{|c|c|c|c|c|c|}
\hline & Baseline & $\mathbf{4}$ weeks & $\mathbf{8}$ weeks & 12 weeks & Signif* $^{*}$ \\
\hline $\begin{array}{c}\text { Mean (SD) } \\
(\mathrm{pd})(\mathrm{N}=18)\end{array}$ & $\begin{array}{c}\text { Mean (SD) (pd) } \\
(\mathrm{N}=16)\end{array}$ & $\begin{array}{c}\text { Mean (SD) (pd) } \\
(\mathrm{N}=14)\end{array}$ & $\begin{array}{c}\text { Mean (SD) (pd) } \\
(\mathrm{N}=13)\end{array}$ & \\
\hline Blur & $11.9(3.9)$ & $15.4(6.9)$ & $14.4(3.7)$ & $16.8(6.8)$ & 0.037 \\
\hline Break & $12.7(3.8)$ & $17.3(6.6)$ & $15.5(3.8)$ & $18.2(6.5)$ & 0.003 \\
\hline Recovery & $9.9(4.0)$ & $13.5(5.1)$ & $12.0(3.3)$ & $14.3(5.5)$ & 0.006 \\
\hline
\end{tabular}

*Repeated measures ANOVA comparing mean at weeks $0,4,8$ and 12

PFV was analyzed as the individual values for blur, break, and recovery (Table 6). Repeated measures ANOVA for PFV showed statistical significance for improvement (increase) in base-out to blur ( $<<0.0001)$, break ( $<<0.0001)$, and recovery $(\mathrm{p}<0.0001)$ from baseline to outcome. Post hoc analysis using Tukey adjusted $p$ values for base-out to blur showed a significant difference between baseline and week $4(\mathrm{p}=0.006)$, baseline and week $8(\mathrm{p}=0.003)$, and baseline and week $12(\mathrm{p}<0.0001)$, but not between any of the other visit to visit comparisons ( $\mathrm{p} \geq 0.18$ ). Post hoc analysis for base-out to break showed a significant difference between baseline and week $4(\mathrm{p}=0.004)$, baseline and week 8 
$(p<0.001)$, and baseline and week $12(p<0.0001)$, but not between any of the other visit to visit comparisons $(\mathrm{p} \geq 0.06)$. Post hoc analysis for base-out to recovery showed a significant difference between baseline and week $4(\mathrm{p}=0.026)$, baseline and week 8 $(\mathrm{p}=0.004)$, baseline and week $12(\mathrm{p}<0.0001)$, and between week 4 and week 12 $(\mathrm{p}=0.043)$.

Table 6. Change in Positive Fusional Vergence

\begin{tabular}{|c|c|c|c|c|c|}
\hline & Baseline & 4 weeks & $\mathbf{8}$ weeks & 12 weeks & Signif* \\
\hline & $\begin{array}{c}\text { Mean (SD) } \\
(\mathrm{pd})(\mathrm{N}=18)\end{array}$ & $\begin{array}{c}\text { Mean (SD) }(\mathrm{pd}) \\
(\mathrm{N}=16)\end{array}$ & $\begin{array}{c}\text { Mean (SD) }(\mathrm{pd}) \\
(\mathrm{N}=14)\end{array}$ & $\begin{array}{c}\text { Mean (SD) }(\mathrm{pd}) \\
(\mathrm{N}=13)\end{array}$ & \\
\hline Blur & $8.7(5.8)$ & $16.1(8.9)$ & $17.2(7.9)$ & $21.3(9.8)$ & $<0.0001$ \\
\hline Break & $11.5(6.6)$ & $18.3(8.3)$ & $20.8(9.0)$ & $24.3(9.2)$ & $<0.0001$ \\
\hline Recovery & $8.6(6.0)$ & $13.7(7.3)$ & $15.2(7.3)$ & $19.2(7.7)$ & $<0.0001$ \\
\hline
\end{tabular}

*Repeated measures ANOVA comparing mean at weeks $0,4,8$ and 12

NPC was analyzed as the individual values for break and recovery (Table 7). Repeated measures ANOVA showed statistical significance for improvement (decrease) in NPC break $(p=0.002)$ and recovery $(p<0.001)$ from baseline to outcome. Post hoc analysis using Tukey adjusted $\mathrm{p}$ values for NPC break showed a significant difference between baseline and week $4(\mathrm{p}=0.009)$, baseline and week $8(\mathrm{p}=0.011)$, and baseline and week $12(p=0.004)$, but not between any of the other visit to visit comparisons $(p \geq 0.95)$. Post hoc analysis for NPC recovery also showed a significant difference between baseline and week $4(p=0.003)$, baseline and week $8(p=0.004)$, and baseline and week 12 $(p<0.001)$, but not between any of the other visit to visit comparisons ( $p \geq 0.91)$. 
Table 7. Change in Near Point of Convergence

\begin{tabular}{|c|c|c|c|c|c|}
\hline & Baseline & $\mathbf{4}$ weeks & $\mathbf{8}$ weeks & 12 weeks & Signif* \\
\hline & $\begin{array}{c}\text { Mean (SD) } \\
(\mathrm{cm})(\mathrm{N}=18)\end{array}$ & $\begin{array}{c}\text { Mean (SD) (cm) } \\
(\mathrm{N}=16)\end{array}$ & $\begin{array}{c}\text { Mean (SD) }(\mathrm{cm}) \\
(\mathrm{N}=14)\end{array}$ & $\begin{array}{c}\text { Mean (SD) (cm) } \\
(\mathrm{N}=13)\end{array}$ & \\
\hline Break & $16.0(8.5)$ & $10.9(7.3)$ & $10.8(7.4)$ & $9.4(8.5)$ & 0.002 \\
\hline Recovery & $20.3(9.6)$ & $14.6(7.7)$ & $14.6(8.5)$ & $12.9(8.6)$ & $<0.001$ \\
\hline
\end{tabular}

*Repeated measures ANOVA comparing mean at weeks 0, 4, 8 and 12

Repeated measures ANOVA showed overall statistical significance for improvement (increase) in vergence facility from baseline to outcome $(p<0.0001)$ (Table 8). Post hoc analysis using Tukey adjusted $p$ values showed a significant difference between baseline and week $4(p<0.001)$, baseline and week $8(p<0.0001)$, baseline and week $12(p<0.0001)$, and between week 4 and week $12(p=0.001)$, but not between the other visit to visit comparisons ( $\mathrm{p} \geq 0.19)$.

Table 8. Vergence Facility

\begin{tabular}{|c|c|c|c|c|c|}
\hline & Baseline & 4 weeks & $\mathbf{8}$ weeks & 12 weeks & Signif* \\
\hline $\begin{array}{c}\text { Mean (SD) } \\
(\mathrm{cpm}) \\
(\mathrm{N}=18)\end{array}$ & $\begin{array}{c}\text { Mean (SD) } \\
(\mathrm{cpm})\end{array}$ & $\begin{array}{c}\text { Mean }(\mathrm{SD}) \\
(\mathrm{N}=16)\end{array}$ & $\begin{array}{c}\text { Mean }(\mathrm{SD}) \\
(\mathrm{N}=14)\end{array}$ & $\begin{array}{c}(\mathrm{cpm}) \\
(\mathrm{N}=13)\end{array}$ & \\
\hline Facility & $4.1(4.4)$ & $9.1(4.8)$ & $11.8(6.6)$ & $14.5(5.9)$ & $<0.0001$ \\
\hline
\end{tabular}

*Repeated measures ANOVA comparing mean at weeks 0, 4, 8 and 12

Repeated measures ANOVA showed overall statistical significance for improvement (decrease) in the CISS from baseline to outcome ( $p=0.0001)$ (Table 9). Post hoc analysis using Tukey adjusted $\mathrm{p}$ values showed a significant difference between 
baseline and week $4(\mathrm{p}=0.007)$, baseline and week $8(\mathrm{p}<0.001)$, and baseline and week 12 $(p=0.001)$, but not between any of the other visit to visit comparisons ( $p \geq 0.50)$.

Table 9. Change in Convergence Insufficiency Symptom Survey

\begin{tabular}{|c|c|c|c|c|c|}
\hline & Baseline & 4 weeks & $\mathbf{8}$ weeks & 12 weeks & Signif* \\
\hline $\begin{array}{c}\text { Mean (SD) } \\
(\mathrm{N}=18)\end{array}$ & $\begin{array}{c}\text { Mean (SD) } \\
(\mathrm{N}=16)\end{array}$ & $\begin{array}{c}\text { Mean (SD) } \\
(\mathrm{N}=14)\end{array}$ & $\begin{array}{c}\text { Mean (SD) } \\
(\mathrm{N}=13)\end{array}$ & \\
\hline Score & $32.1(13.2)$ & $25.6(14.5)$ & $22.8(13.1)$ & $22.5(13.7)$ & 0.0001 \\
\hline
\end{tabular}

*Repeated measures ANOVA comparing mean at weeks $0,4,8$ and 12

\section{$\underline{\text { Kinetics of Change }}$}

Figures 8-12 illustrate the kinetics of change in each outcome measure from baseline to outcome by plotting the means of each outcome measure at each visit.

Figure 8. Kinetics of Change in NFV

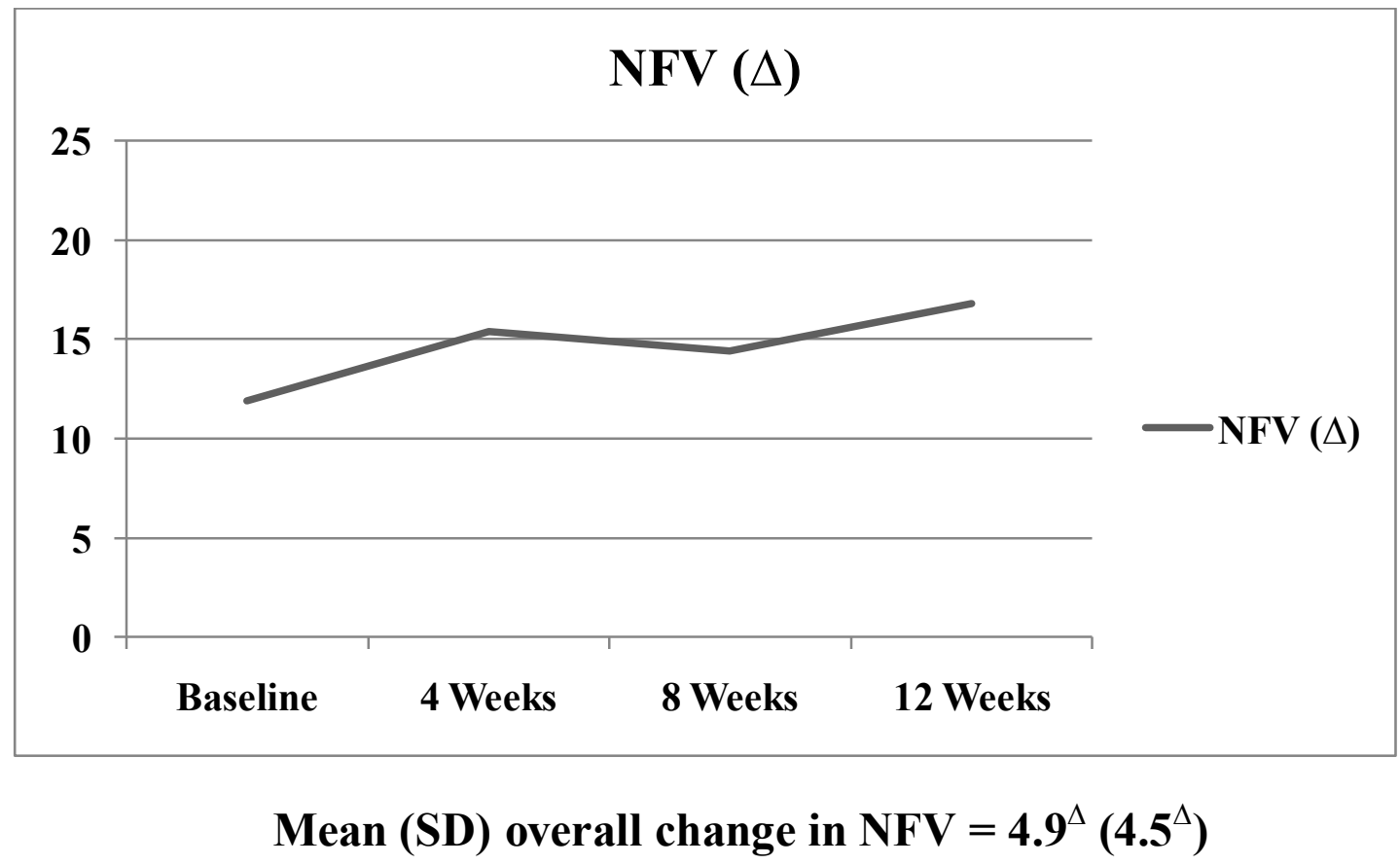


Figure 9. Kinetics of Change in PFV

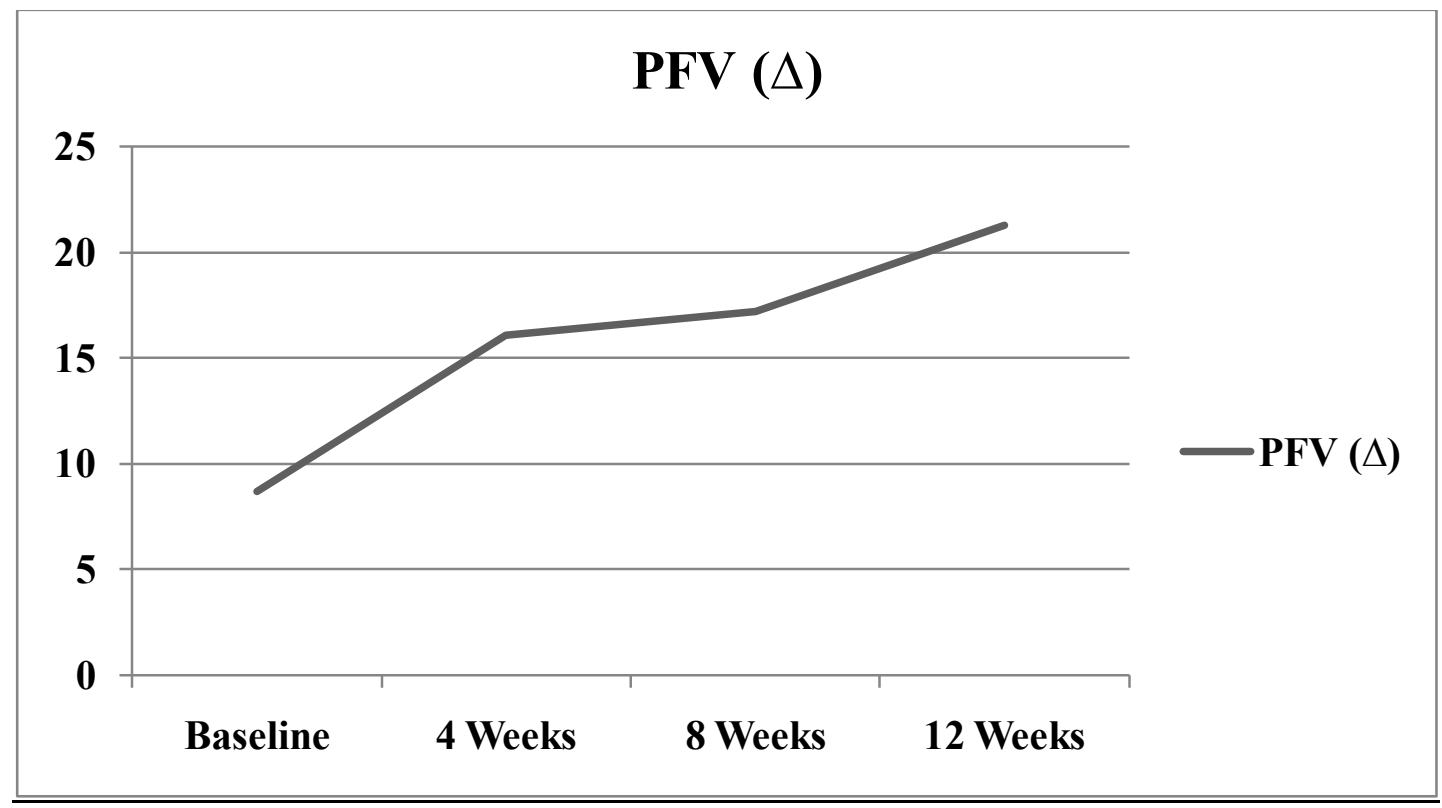

Mean (SD) overall change in $\mathrm{PFV}=11.8^{\Delta}\left(12.2^{\Delta}\right)$

Figure 10. Kinetics of Change in NPC

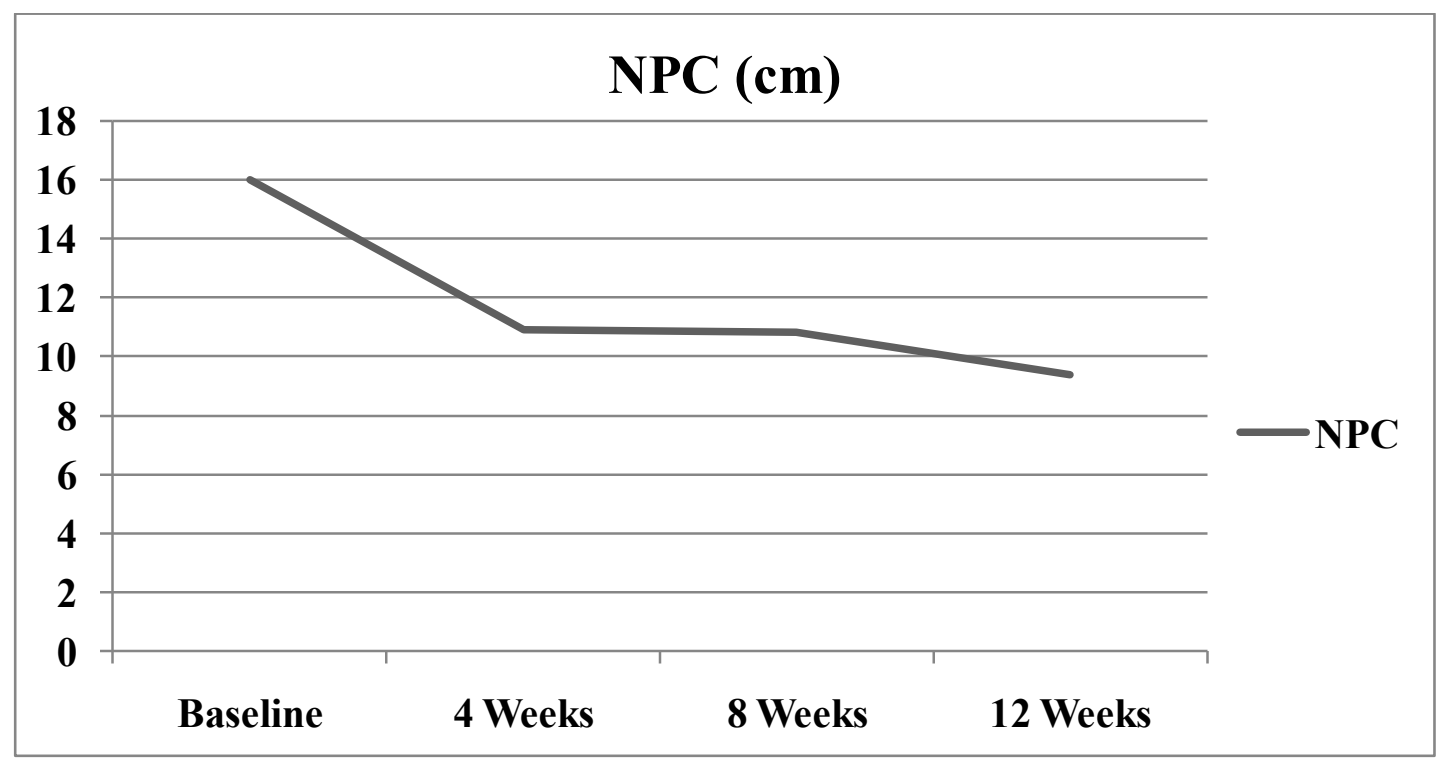

Mean (SD) overall change in $\mathrm{NPC}=6.8 \mathrm{~cm}(9.2 \mathrm{~cm})$ 
Figure 11. Kinetics of Change in VF

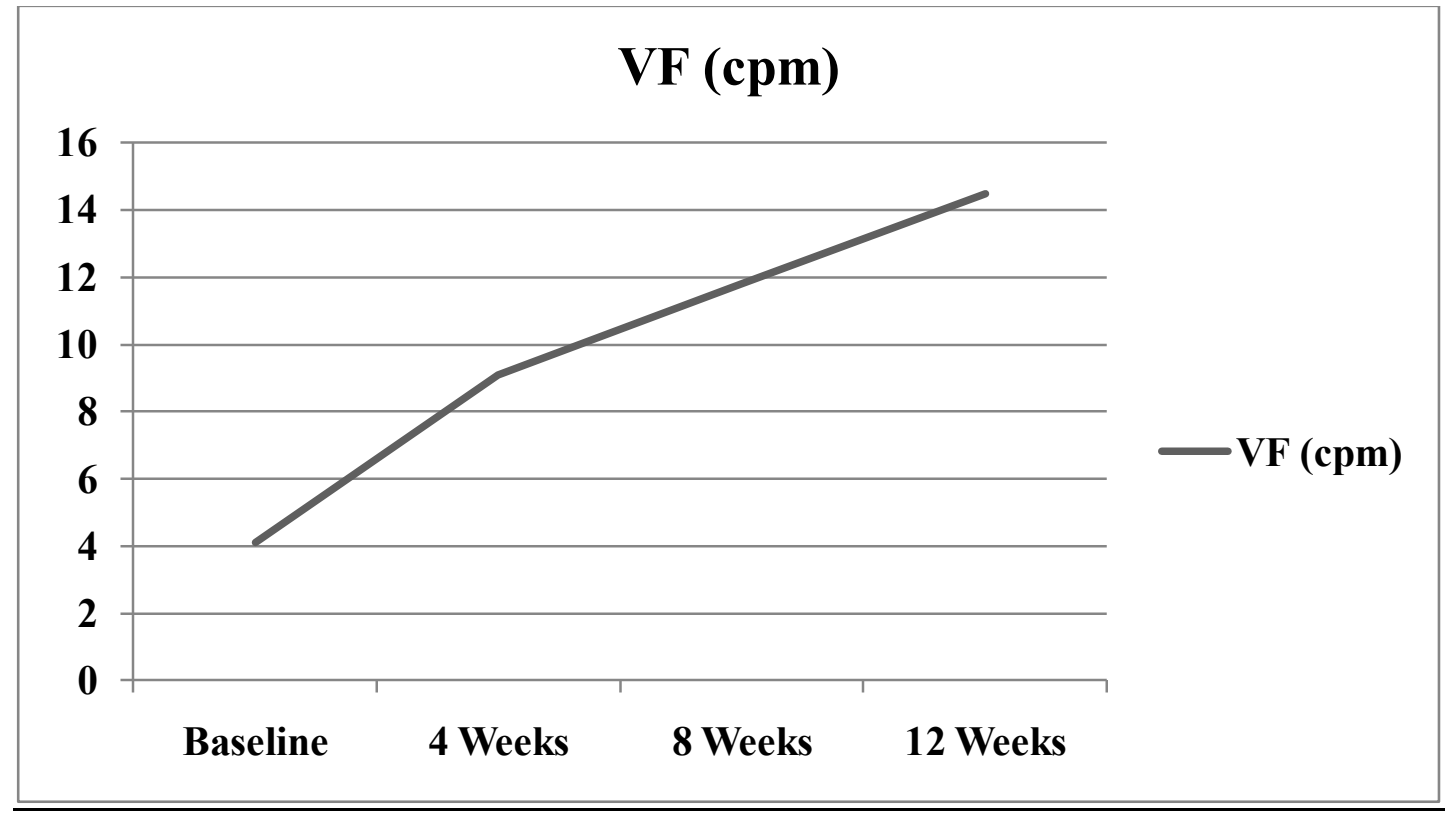

Mean (SD) overall change in VF $=10.2 \mathrm{cpm}(5.6 \mathrm{cpm})$

Figure 12. Kinetics of Change in CISS

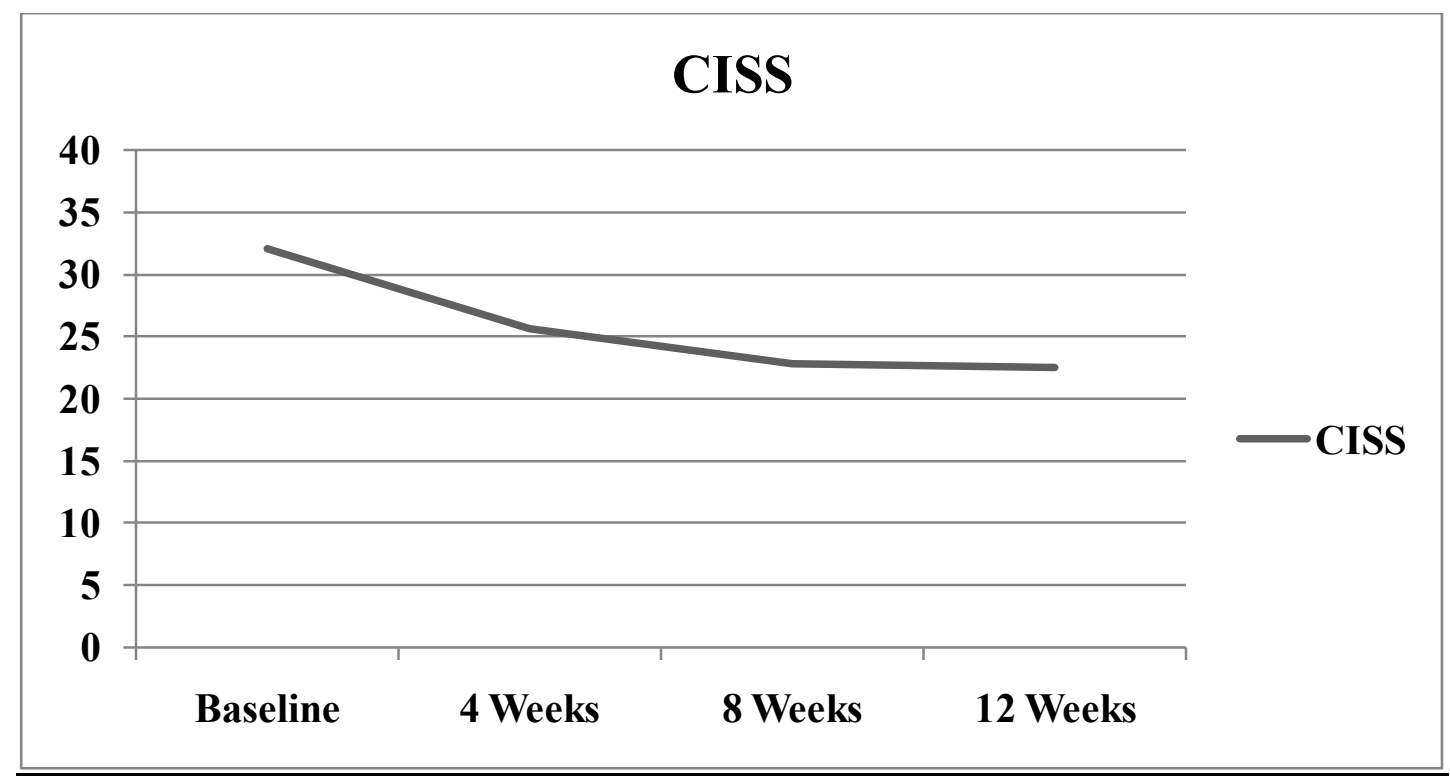

Mean (SD) overall change in CISS $=7.0$ (7.7) 


\section{Analysis Using Sheard's Criterion}

Sheard's criterion states that comfortable binocular vision can be expected if the compensating fusional vergence is at least twice the magnitude of the heterophoria. ${ }^{61}$ Therefore, the ratio of compensating vergence / phoria for each subject (who completed the outcome visit) also was plotted at baseline and outcome to evaluate change in the fusional vergence to phoria relationship.

Figure 13. Sheard's Criterion at Baseline

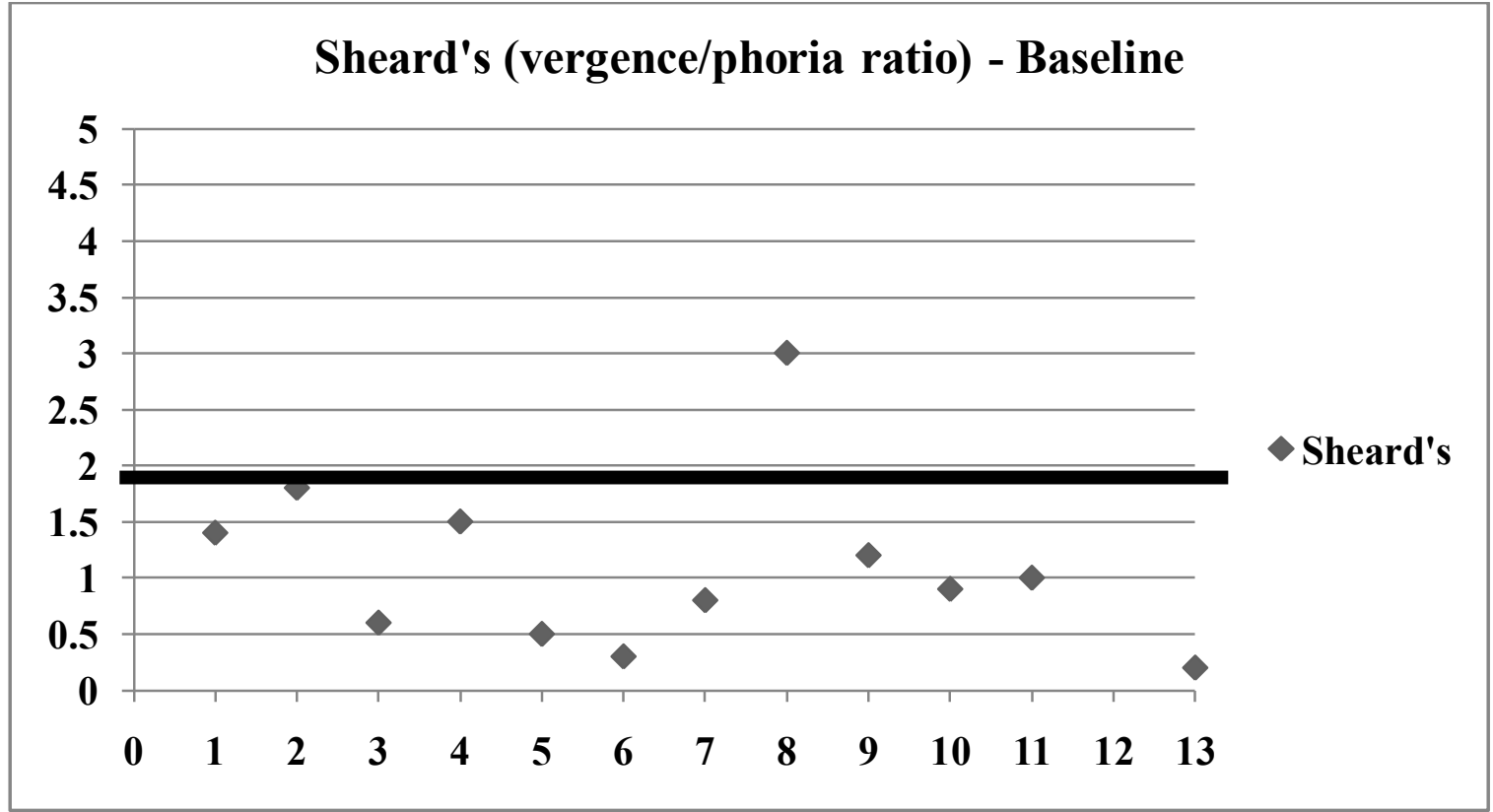

Note: Subject 12 does not have a data point due to orthophoria. Subject 8 met Sheard's criterion, but did not have a normal level of PFV (i.e. $>15 \Delta$ ). 
Figure 14. Sheard's Criterion Post Therapy

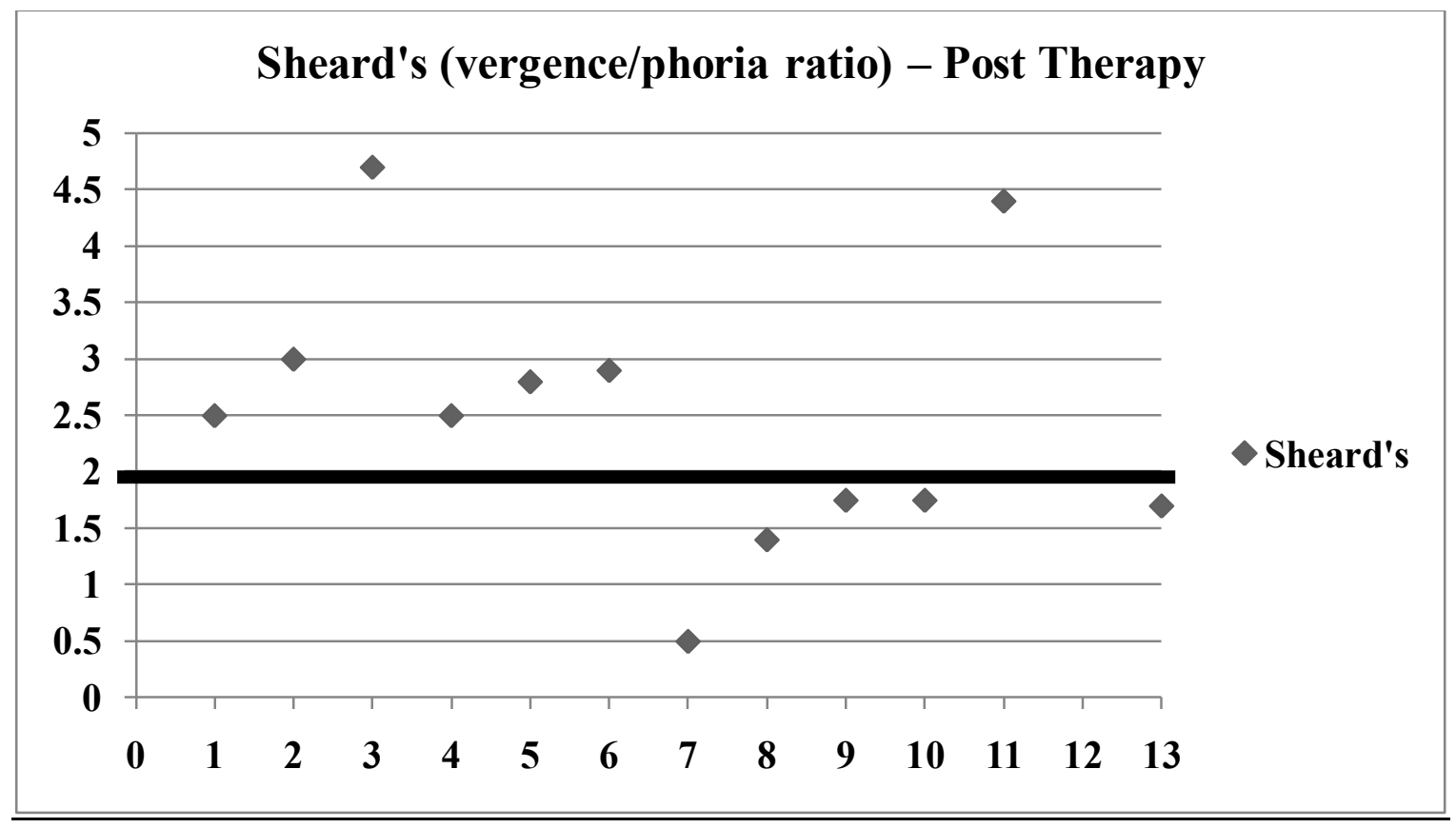

Note: Subject 12 does not have a data point due to orthophoria.

$\underline{\text { Analysis of Success and Improvement }}$

The percentage of subjects (of those who completed the final outcome visit) who were classified as "successful" or improved in both NPC and PFV as well as for each measure was determined (Table 10). 
Table 10. Success and Improvement

\begin{tabular}{|c|c|c|}
\hline Variable & \% Successful & $\begin{array}{c}\text { \% Successful or } \\
\text { Improved }\end{array}$ \\
\hline CISS & $54 \%$ & $62 \%$ \\
\hline NPC & $46 \%$ & $69 \%$ \\
\hline PFV & $69 \%$ & $77 \%$ \\
\hline NFV & $77 \%$ & $77 \%$ \\
\hline PFV and NFV & $69 \%$ & $69 \%$ \\
\hline Vergence Facility & $69 \%$ & $92 \%$ \\
\hline NPC and PFV composite & $54 \%$ & $62 \%$ \\
\hline
\end{tabular}




\section{DISCUSSION}

\section{$\underline{\text { Summary of Results }}$}

In this study, subjects with binocular dysfunction secondary to brain injury were shown to have improved near point of convergence, negative fusional vergence, positive fusional vergence, vergence facility, and reduced symptoms following a 12 week program of home based computer therapy. The majority of the subjects suffered from TBI.

\section{Comparison with Previous Studies}

In the Ciuffreda, et al retrospective review of brain injured patients ${ }^{23}$, the individuals who received vision therapy as treatment were analyzed. In his review $(\mathrm{n}=40), 33$ suffered from TBI and 7 suffered from CVA comparing well with 15 suffering from TBI, 3 from CVA, and 1 from organic insult in the present study. Signs and symptoms at baseline compared well between the two studies. Receded near point of convergence and deficits in positive fusional vergence were features of the brain injured groups from both studies. A major difference in methodology is that in Ciuffreda's review, conventional optometric vision therapy techniques were used in the form of inoffice therapy in most cases. In the present study, only home based computer therapy was used. Ninety percent of TBI patients and $100 \%$ of CVA patients were classified as 
successful upon analysis of Ciuffreda's retrospective review. The success criterion in Ciuffreda's study was "either marked improvement or normalization of at least 1 primary symptom and at least 1 primary sign." No survey instrument was used for assessing symptoms. Rather, a common clinical employment of no improvement, some improvement, or marked/total improvement categories was used. For signs, an improvement towards compensatory values relative to heterophoria or towards normative values in the absence of heterophoria was used. ${ }^{23}$ Therefore, it is not possible to directly compare results between the present and Ciuffreda's studies due to differences in methodology.

Cooper's retrospective study evaluated change in symptoms after completing computer based therapy in prepresbyopic patients with vergence and accommodative disorders $(n=43) .^{72}$ The software used was HTS and the symptom instrument was the CISS, the same as was used in the present study. Cooper's review showed a mean reduction in symptoms with a baseline value of $32.1(\mathrm{SD}=8.1)$ and a post therapy value of 20.6 $(\mathrm{SD}=11.5)$. This compares well with the present study with a baseline value of 32.1 $(\mathrm{SD}=13.2)$ and a post therapy value of $22.5(\mathrm{SD}=13.7)$.

Scheiman and Gallaway's report ${ }^{48}$ described several cases that are representative of brain injured patients that come through practices. The first case presented nine months after TBI with symptoms of blurred vision and headaches after short periods of time when reading with clinical signs of receded NPC, reduced PFV, reduced vergence facility, and intermittent exotropia at near. After vision therapy, all signs were significantly improved and symptoms were significantly reduced. This case is a good representation of several individuals that participated in the present study. Scheiman and 
Gallaway also report an unsuccessful case. This TBI case presented one year after injury with inability to read comfortably after short periods of time with headaches and diplopia. Clinical signs showed severely receded NPC, severely reduced PFV, and inability to complete a cycle of vergence facility. Even after multiple reevaluations throughout the 36 session in-office therapy program, the individual showed zero improvement. The authors bring up factors that may have affected the outcome including frequent absences, poor carry over from one session to the next, memory problems, and frequent loss of attention. The present study had one participant with many similarities, including severe clinical signs and severe symptoms. This individual was compliant with the therapy session schedule and with status evaluations, but also showed no improvement on signs and symptoms. This subject had intermittent strabismus and therefore, may have had more difficulty at home consistently achieving random dot stereopsis due to intermittent loss of fusion.

Significant improvement in binocular function following vision therapy in the brain injured population has been reported in retrospective reviews of medical records, case reports, and case series. Finding improvement in binocularity in this prospective study of brain injured subjects supports the findings from prior retrospective studies.

One alternative explanation of the study's results is that the natural history of the injury relative to binocular vision resolved during the treatment period. This is unlikely due to the fact that the study sample included brain injured individuals that had varying amounts of time elapsed since the injury, ranging from months to many years (4.2 years on average for those who completed the study). 
Another consideration is the possibility of a placebo effect. It is possible that simply the participation in a prescribed therapy program had a positive effect on a subject's perception of the condition. ${ }^{73}$ A placebo controlled study is needed to determine whether a placebo effect is present.

\section{$\underline{\text { Treatment Modality }}$}

The CITT group showed that office-based vergence/accommodative therapy (OBVAT) was most effective in treating convergence insufficiency in children age 9-17. It may seem reasonable then, to select this modality as a first choice in designing a study for treatment of binocular dysfunction in brain injured individuals. However, home-based computer therapy was selected for the present study due to time constraints, the fact that this type of therapy is commonly used in practice, and the CITT showed that this type of therapy did have positive effects on signs. In addition, subjects were required to have access to the internet which allowed closer follow-up. The central database reporting feature of HTS enabled the investigator to view when sessions were completed and what level was achieved. This enabled the ability to track compliance and troubleshoot problems that subjects may have had. Furthermore, the computer based modality enabled the subject to perform therapy at home on a flexible schedule which was advantageous in cases of transportation and mobility difficulties. It also enabled the subject to complete shorter therapy sessions (20 minutes) than a typical in-office schedule (1 hour), which was advantageous for subjects who experienced fatigue even after short therapy sessions. 
A disadvantage of HTS that arose during this study was the fixed goal that is set within the software for achievement, particularly on base-out vergence. In this population the set goal $\left(>35^{\Delta} \mathrm{BO}\right)$ was often unachievable; therefore, this prevented subjects from achieving 'gold stars' and progressing to other procedures (autoslide and jump ductions). This was discouraging for some subjects and it is possible that the ability to individualize the goals for each subject may result in better overall success.

Symptoms

A significant improvement (decrease) in CISS was found using ANOVA with the mean score decreasing from a mean of $32.1(+/-13.2)$ at baseline to a mean of 22.5 $(+/-13.7)$ at outcome. However, only $62 \%$ of subjects met the criteria for successful or improved on the CISS. The CISS score of 21 was used as a cutoff based on the CITT group's report which showed that a score of 21 distinguished between adults ages 19 to 30 years with symptomatic CI versus those without binocular vision disorders. ${ }^{56}$ However, the best cut-off for older adults and for adults with brain injury is unknown. It is possible that the appropriate cutoff score on the CISS to distinguish between brain injured individuals with and without normal binocular vision may be higher than in the non-brain injured adult population. One contributing factor may be that non-visual effects of the brain injury are present and increase the score. For example, headaches (Question \#3) may be more common in some instances following brain injury irrespective of deficits in binocular vision. Other examples include loss of concentration and difficulty remembering what was read (Question \#5 and \#6, respectively), which may be more common in a brain injured individual. 


\section{Neurology of Improved Signs}

The specifics of the underlying neurology regarding improvements with vision therapy are unknown. Some surmise that neuroplastic changes occur over the course of a therapeutic time period. Others argue that the normal pathways for the appropriate eye movements and focusing are intact, but visual attention is lacking. In this view, vision therapy is a means by which visual attention to the task at hand, retinal disparity, and retinal defocus is improved. As functional neuroimaging (e.g. fMRI) becomes a more commonly employed tool in research, the changes that occur throughout treatment will become better understood. In prescribing vision therapy to adults with convergence insufficiency, Alvarez, et al found a significant correlation between improvement in clinical signs and increased brain activity on fMRI. It is unknown whether this change was due to neuroplastic changes or improved visual attention. Because rapid improvement in signs has been reported by vision therapy studies (CITT, present study), improvement in visual attention may be more plausible than a substantial anatomical and functional reorganization of the neurological substrate.

\section{$\underline{\text { Success on Vergence Facility }}$}

The mean improvement of vergence facility from the baseline visit to the outcome visit outpaced the other outcome measures. This is illustrated by the graph of the kinetics of change which shows a nearly linear increase in mean vergence facility throughout the study. One factor contributing to this disparity may be the fact that as a group, the mean PFV at baseline was less than the $12 \Delta$ base-out required to complete one cycle of vergence facility and 9 subjects had vergence facility measuring less than $1 \mathrm{cpm}$ at 
baseline. At the four week follow up visit, the mean PFV of the group had increased to greater than $15 \Delta$ and only one subject could not complete at least $1 \mathrm{cpm}$. Nevertheless, Melville and Firth suggest that fusional vergence ranges and vergence facility shed light on different aspects of the vergence system. They hypothesized that the PFV ranges are associated with the slow fusional vergence system and that vergence facility is associated with the fast fusional vergence system. ${ }^{68}$ McDaniel and Fogt confirmed the lack of correlation between PFV and vergence facility. ${ }^{69}$ They hypothesized that the presence of vergence adaptation could be responsible for the lack of correlation. However, equal amounts of vergence adaptation were found during both vergence ranges and vergence facility testing indicating that the fast fusional vergence system is at least partially responsible for the vergence range response. It remains evident that different aspects of the vergence system contribute to the ability to perform fusional vergence ranges and vergence facility.

\section{Implications for Practice}

Depending on the severity of brain injury, many individuals do not receive timely visual and ocular evaluation. Instances in which a visual evaluation is pursued often only include a focus on visual acuity and visual field. While these assessments are of paramount importance and should not be displaced as a top priority, the lingering nature of binocular vision deficits should not be ignored. A separate evaluation (e.g. a sensorimotor exam) should be performed on a day other than that of the primary eye care assessment following a brain injury. This will help avoid fatigue, which may be commonly observed. A focused sensorimotor exam will elicit any binocular dysfunction. 
In this way, an appropriate treatment plan can be established. The results of this study showed that the majority of subjects who were compliant with therapy experienced meaningful improvements in signs and symptoms. It is not known whether greater improvements would have been found with an increased duration or frequency of homebased therapy sessions or with office-based therapy. There was a high loss to follow-up and it is not known whether those who were unsuccessful in the present study, would have benefited from a different mode of therapy.

\section{Limitations of the Study}

Limitations include a small sample size, lack of multiple treatment arms with placebo control, lack of masking, lack of pre-presbyopic individuals to assess and treat accommodative dysfunction, a high loss to follow-up, and lack of knowledge of whether the binocular dysfunction was present prior to brain injury.

\section{$\underline{\text { Directions for Future Research }}$}

This study showed that the majority of subjects who were compliant with homebased computer vision therapy experienced meaningful improvements in signs and symptoms. These results supports retrospective reports in the literature which have found that therapy can result in a successful or improved outcome in binocular vision function. However, the current literature is not able to instruct the practitioner, regarding ideal treatment modality, treatment procedures, ideal treatment frequency, treatment duration, need for maintenance, and patient characteristics that may assist in predicting success.

Due to the high incidence of brain injury in the United States and worldwide, the high 
frequency of associated binocular dysfunction, and the impact of binocular dysfunction on the quality and functioning of daily activities, further research is necessary. A well designed, randomized, placebo controlled clinical trial is needed to provide the information necessary regarding the best treatment for common binocular vision conditions in this unique population in order to assist in the restoration of quality of life. 


\section{CONCLUSION}

Twelve weeks of home-based computer therapy resulted in meaningful improvements in signs and symptoms for the majority of adults with binocular vision dysfunction post brain injury that were compliant with the therapy program. Further research should be conducted to determine the best treatment for managing binocular dysfunction post brain injury. 


\section{REFERENCES}

1) Elovic, E. and T. Antoinette. (1996). Epidemiology and Primary Prevention of Traumatic Brain Injury. In L. Horn \& N. Zasler (Eds.), Medical Rehabilitation of Traumatic Brain Injury (pp. 1-24). Philadelphia: Hanley \& Belfus, Inc.

2) Harrison CL, Dijkers M. Traumatic Brain Injury Registries in the United States: An overview. Brain Injury 6:203-212, 1992.

3) Menon, D., et. al. Position Statement: Definition of Traumatic Brain Injury. (2010). American Congress of Rehabilitation Medicine. Elsevier, Inc.

4) Langlois, J. A., W. Rutland-Brown, et al. (2006). "The epidemiology and impact of traumatic brain injury: a brief overview." J Head Trauma Rehabil 21(5): 375 378.

5) Iverson, G., et. al. (2007). Mild TBI. In N. Zasler, D. Katz, and R. Zafonte (Eds.), Brain Injury Medicine (pp. 331-361). New York: Demos Medical Publishing, LLC.

6) Troncoso, J. and B. Gordon. (1996). Neuropathology of Closed Head Injury. In M. Rizzo \& D. Tranel (Eds.), Head Injury and Postconcussive Syndrome (pp. 4756). New York: Churchill Livingstone.

7) Signoretti, S., R. Vagnozzi, et al. (2010). "Biochemical and neurochemical sequelae following mild traumatic brain injury: summary of experimental data and clinical implications." Neurosurg Focus 29(5): E1.

8) Baron, E. and J. Jallo. (2007). TBI: Pathology, Pathophysiology, Acute Care and Surgical Management, Critical Care Principles, and Outcomes. In N. Zasler, D. Katz, and R. Zafonte (Eds.), Brain Injury Medicine (pp. 265-279). New York: Demos Medical Publishing, LLC.

9) Kochanek, P. and R. Clark and L. Jenkins. (2007). TBI: Pathobiology. In N. Zasler, D. Katz, and R. Zafonte (Eds.), Brain Injury Medicine (pp. 81-92). New York: Demos Medical Publishing, LLC.

10) Povlishock, JT: Pathophysiology of neural injury: therapeutic opportunities and challenges. Clin Neurosurg 2000; 46:113-126.

11) Marion, D. (1996). Pathophysiology and Initial Neurosurgical Care: Future Directions. In L. Horn \& N. Zasler (Eds.), Medical Rehabilitation of Traumatic Brain Injury (pp. 29-47). Philadelphia: Hanley \& Belfus, Inc. 
12) Gianutsos R, Suchoff IB. Neuropsychological consequences of mild brain injury and optometric implications. J Behav Optom 1998;9(1):3-6.

13) Hellerstein, L. F., S. Freed, et al. (1995). "Vision profile of patients with mild brain injury." J Am Optom Assoc 66(10): 634-639.

14) Center for Disease Control and Prevention. Traumatic Brain Injury in the United States: a report to Congress. Volume 2005, 2003.

15) Goldstein, et al. Guidelines for the Primary Prevention of Stroke. Stroke. American Heart Association, 2010.

16) Khan, S. et. al. Stroke and Visual Rehabilitation. Top Stroke Rehabil. 2008 JanFeb;15(1):27-36.

17) Kerkhoff G. Neurovisual rehabilitation: recent developments and future directions. J Neurol Neurosurg Psychiatry. 2000;68:691-706.

18) MacIntosh C. Stroke re-visited: visual problems following stroke and their effect on rehabilitation. Br Orthopt J. 2003;60(1):10-14.

19) Ciuffreda, K. J., N. Kapoor, et al. (2007). "Occurrence of oculomotor dysfunctions in acquired brain injury: a retrospective analysis." Optometry 78(4): 155-161.

20) Rosen, S.A., Cohen, A.H., Trebling, S. (2001) The integration of visual and vestibular systems in balance disorder - a clinical perspective. In Suchoff, I.B., Ciuffreda, K.J., Kapoor, N. (eds.): Visual \& Vestibular Consequences of Acquired Brain Injury. Santa Ana: Optometric Extension Program, pp. 174-200.

21) Padula, W.V. (1988a) Chapter VI: The neuro-optometric rehabilitation examination. In Padula, W.V. (ed.): Neuro-Optometric Rehabilitation, 3rd ed. Santa Ana: Optometric Extension Program, pp. 78-87.

22) Padula, W. V., S. Argyris, et al. (1994). "Visual evoked potentials (VEP) evaluating treatment for post-trauma vision syndrome (PTVS) in patients with traumatic brain injuries (TBI)." Brain Inj 8(2): 125-133.

23) Ciuffreda, K. J., D. Rutner, et al. (2008). "Vision therapy for oculomotor dysfunctions in acquired brain injury: a retrospective analysis." Optometry 79(1): $18-22$.

24) Cohen M, Groswasser Z, Barchadski R, Appel A. "Convergence insufficiency in brain -injured patients." Brain Inj 1989; 3: 187-191.

25) Lepore, F. E. (1995). "Disorders of ocular motility following head trauma." Arch Neurol 52(9): 924-926. 
26) Sabates, N. R., M. A. Gonce, et al. (1991). "Neuro-ophthalmological findings in closed head trauma." J Clin Neuro-ophthalmol 11(4): 273-277.

27) Padula WV, Argyris S. "Post trauma vision syndrome and visual midline shift syndrome." NeuroRehabilitation. 1996;6:165-171. 93

28) Padula, WV. "Modifying postural adaptation following a CVA through prismatic shift of visuo-spatial egocenter." Brain Inj. 2009 Jun;23(6):566-76.

29) Scheiman, et al. "The convergence insufficiency treatment trial: design, methods, and baseline data." Convergence Insufficiency Treatment Trial (CITT) Study Group. Ophthalmic Epidemiol. 2008 Jan-Feb;15(1):24-36.

30) Scheiman, $M$ et al. "A randomized clinical trial of treatments for convergence insufficiency in children.” Arch Ophthalmol. 2005 Jan;123(1):14-24.

31) Scheiman, $M$ et al. "Randomized clinical trial of treatments for symptomatic convergence insufficiency in children." Convergence Insufficiency Treatment Trial Study Group. Arch Ophthalmol. 2008 Oct;126(10):1336-49.

32) Lavrich JB. "Convergence insufficiency and its current treatment." Curr Opin Ophthalmol. 2010 Sep;21(5):356-60.

33) Scheiman, M et al. "Long-term effectiveness of treatments for symptomatic convergence insufficiency in children." Convergence Insufficiency Treatment Trial Study Group. Optom Vis Sci. 2009 Sep;86(9):1096-103.

34) Scheiman, $\mathrm{M}$ et al. "Vision therapy/orthoptics for symptomatic convergence insufficiency in children: treatment kinetics." Convergence Insufficiency Treatment Trial Study Group. Optom Vis Sci. 2010 Aug;87(8):593-603.

35) Cohen, A. H. and R. Soden (1984). "Effectiveness of visual therapy for convergence insufficiencies for an adult population." J Am Optom Assoc 55(7): 491-494.

36) Birnbaum, M. H., R. Soden, et al. (1999). "Efficacy of vision therapy for convergence insufficiency in an adult male population." J Am Optom Assoc 70(4): 225-232.

37) Krohel, GB, RW Kristan, et al. (1986). "Posttraumatic convergence insufficiency." Ann Ophthalmol 18(3): 101-102, 104.

38) Sabel, B. A., S. Matzke, et al. (2010). "Special issues in brain plasticity, repair and rehabilitation: 20 years of a publishing strategy." Restor Neurol Neurosci 28(6): 719-728.

39) Sabel, B. A. (2008). "Plasticity and restoration of vision after visual system damage: an update." Restor Neurol Neurosci 26(4-5): 243-247.

40) Green, W., K. J. Ciuffreda, et al. (2010). "Accommodation in mild traumatic brain injury." J Rehabil Res Dev 47(3): 183-199. 
41) Green, W., K. J. Ciuffreda, et al. (2010). "Static and dynamic aspects of accommodation in mild traumatic brain injury: a review." Optometry 81(3): 129136.

42) Brahm, K. D., H. M. Wilgenburg, et al. (2009). "Visual impairment and dysfunction in combat-injured servicemembers with traumatic brain injury." Optom Vis Sci 86(7): 817-825.

43) Kapoor, N. and K. J. Ciuffreda (2002). "Vision Disturbances Following Traumatic Brain Injury." Curr Treat Options Neurol 4(4): 271-280.

44) Burde, R., et. al. (2002). Postchiasmal Visual Loss. In R. Burde, P. Savino, and J. Trobe (Eds.) Clinical Decisions in Neuro-Ophthalmology (pp. 83-91). St. Louis: Mosby.

45) Padula, W., et. al. (2007). Evaluating and Treating Visual Dysfunction. In N. Zasler, D. Katz, and R. Zafonte (Eds.), Brain Injury Medicine (pp. 511-526). New York: Demos Medical Publishing, LLC.

46) American Academy of Optometry and American Optometric Association (AAO/AOA). Optometric Care of the Patient with Acquired Brain Injury. A Joint Organizational Policy Statement of the American Academy of Optometry and the American Optometric Association. J Am Optom Assoc. 2003.

47) Hiatt, J. and L Gartner. (2002). Cranial Nerves. In J. Hiatt and L. Gartner (Eds.), Textbook of Head and Neck Anatomy (pp. 259-291). Philadelphia: Lippincott Williams and Wilkins.

48) Scheiman, M and M. Gallaway. (2001). Vision Therapy to Treat Binocular Vision Disorders After Acquired Brain Injury: Factors Affecting Prognosis. In I. Suchoff, K. Ciuffreda, and N. Kapoor (Eds.), Visual \& Vestibular Consequences Of Acquired Brain Injury (pp. 89-113). Santa Ana, CA: Optometric Extension Program.

49) Stein, D. (2007). Concepts of CNS Plasticity and Their Implications for Understanding Recovery After Brain Damage. In N. Zasler, D. Katz, and R. Zafonte (Eds.), Brain Injury Medicine (pp. 97-108). New York: Demos Medical Publishing, LLC.

50) Boyeson, M. and J. Jones. (1996). Theoretical Mechanisms of Brain Plasticity and Therapeutic Implications. In L. Horn \& N. Zasler (Eds.), Medical Rehabilitation of Traumatic Brain Injury (pp. 77-102). Philadelphia: Hanley \& Belfus, Inc.

51) Kandel ER, Schwartz JH, Jessell TM: Principles of Neural Science. New York, McGraw-Hill, 2000.

52) Spear PD. (1977). Behavioral and neurophysiological consequences of visual cortex damage. In J. Sprague and A. Epstein (Eds.), Progress in Psychobiology and Physiological Psychology, vol. 8 (pp 45-83). New York: Academic Press. 
53) Huang, JC. Neuroplasticity as a Proposed Mechanism for the Efficacy of Optometric Vision Therapy \& Rehabilitation. J Behav Optom 2009;20:95-99.

54) Hokoda SC. General binocular dysfunction in an urban optometry clinic. J Am Optom Assoc 1985;56:560-2.

55) Scheiman, et al. "A Randomized Clinical Trial of Vision Therapy/Orthoptics versus Pencil Pushups for the Treatment of Convergence Insufficiency in Young Adults." Optometry \& Vision Science 2005;82:583-595.

56) Rouse, et al. "Validity and reliability of the revised convergence insufficiency symptom survey in adults." Ophthal Physiol Opt 2004 24: 384-390.

57) Finkelstein E, Corso $P$, Miller $T$ and associates. The Incidence and Economic Burden of Injuries in the United States. New York (NY): Oxford University Press; 2006.

58) Schor, CM. Influence of accommodative and vergence adaptation on binocular motor disorders. Am J Optom Physiol Opt 65:464-475, 1988.

59) Schor, CM. The Glenn A. Fry Award Lecture: Adaptive regulation of accommodative vergence and vergence accommodation. Am J Optom Physiol Opt 63:587-609, 1986.

60) Alvarez, $\mathrm{T}$ et al. "Vision Therapy in Adults with Convergence Insufficiency: Clinical and Functional Magnetic Resonance Imaging Measures." Optometry \& Vision Science 2010;87:985-1002.

61) Sheard C. "Zones of ocular comfort.” Am J Optom 1930;7:9-25.

62) Vallar, G and D Perani. The anatomy of unilateral neglect after right-hemisphere stroke lesions. A clinical/CT-scan correlation study in man. Neuropsychologia. 1986;24(5):609-22.

63) Karnath, HO. Spatial awareness is a function of the temporal not the posterior parietal lobe. Nature. 2001 Jun 21;411(6840):950-3.

64) Mort, DJ et al. The anatomy of visual neglect. Brain. 2003 Sep;126(Pt 9):198697. Epub 2003 Jun 23.

65) Bird, CM et al. Visual neglect after right posterior cerebral artery infarction. $\underline{\mathrm{J}}$ Neurol Neurosurg Psychiatry. 2006 Sep;77(9):1008-12. Epub 2006 Jun 13.

66) Albert, ML. A simple test of visual neglect. Neurology. 1973 Jun;23(6):658-64.

67) Scheiman, M. and B. Wick (eds.). Clinical Management of Binocular Vision: Heterophoric, Accommodative, and Eye Movement Disorders, $3^{\text {rd }}$ edition. Philadelphia: Lippincott Williams \& Wilkins, 2008.

68) Melville, A. and A.Y. Firth. Is there a relationship between prism fusion range and vergence facility? Br Orthopt J 59 (2002), pp. 38-44.

69) McDaniel, C and N Fogt. Vergence adaptation in clinical vergence testing. Optometry. 2010 Sep;81(9):469-75. Epub 2010 Jul 23. 
70) Leigh, RJ and DS Zee, Eds. The Neurology of Eye Movements ( $2^{\text {nd }}$ Edition). Philadelphia: FA Davis Company, 1991.

71) King, N. "Mild head injury: neuropathology, sequelae, measurement and recovery." Br J Clin Psychol. 1997 May;36 ( Pt 2):161-84.

72) Cooper J, Feldman J. "Reduction of symptoms in binocular anomalies using computerized home therapy-HTS.” Optometry. 2009 Sep;80(9):481-6.

73) de la Fuente-Fernandez R, Schulzer M, Stoessl AJ. "The placebo effect in neurological disorders." Lancet Neurol. 2002;1:85-91. 


\section{APPENDIX A:}

\section{CONVERGENCE INSUFFCIENCY}

SYMPTOM SURVEY 


\section{Convergence Insufficiency Symptom Survey}

Clinician instructions: Read the following subject instructions and then each item exactly as written. If subject responds with "yes" - please qualify with frequency choices. Do not give examples.

Subject instructions: Please answer the following questions about how your eyes feel when reading or doing close work.

\begin{tabular}{|c|c|c|c|c|c|c|}
\hline & & Never & $\begin{array}{c}\text { (not very } \\
\text { often) } \\
\text { Infrequently }\end{array}$ & Sometimes & $\begin{array}{l}\text { Fairly } \\
\text { often }\end{array}$ & Always \\
\hline 1. & $\begin{array}{l}\text { Do your eyes feel tired when reading } \\
\text { or doing close work? }\end{array}$ & & & & & \\
\hline 2. & $\begin{array}{l}\text { Do your eyes feel uncomfortable } \\
\text { when reading or doing close work? }\end{array}$ & & & & & \\
\hline 3. & $\begin{array}{l}\text { Do you have headaches when } \\
\text { reading or doing close work? }\end{array}$ & & & & & \\
\hline 4. & $\begin{array}{l}\text { Do you feel sleepy when reading or } \\
\text { doing close work? }\end{array}$ & & & & & \\
\hline 5. & $\begin{array}{l}\text { Do you lose concentration when } \\
\text { reading or doing close work? }\end{array}$ & & & & & \\
\hline 6. & $\begin{array}{l}\text { Do you have trouble remembering } \\
\text { what you have read? }\end{array}$ & & & & & \\
\hline 7. & $\begin{array}{l}\text { Do you have double vision when } \\
\text { reading or doing close work? }\end{array}$ & & & & & \\
\hline 8. & $\begin{array}{l}\text { Do you see the words move, jump, } \\
\text { swim, or appear to float on the page } \\
\text { when reading or doing close work? }\end{array}$ & & & & & \\
\hline 9. & Do you feel like you read slowly? & & & & & \\
\hline 10. & $\begin{array}{l}\text { Do your eyes ever hurt when reading } \\
\text { or doing close work? } \\
\end{array}$ & & & & & \\
\hline 11. & $\begin{array}{l}\text { Do your eyes ever feel sore when } \\
\text { reading or doing close work? }\end{array}$ & & & & & \\
\hline 12. & $\begin{array}{l}\text { Do you feel a "pulling" feeling around } \\
\text { your eyes when reading or doing } \\
\text { close work? }\end{array}$ & & & & & \\
\hline 13. & $\begin{array}{l}\text { Do you notice the words blurring or } \\
\text { coming in and out of focus when } \\
\text { reading or doing close work? }\end{array}$ & & & & & \\
\hline 14. & $\begin{array}{l}\text { Do you lose your place while reading } \\
\text { or doing close work? } \\
\end{array}$ & & & & & \\
\hline 15. & $\begin{array}{l}\text { Do you have to re-read the same line } \\
\text { of words when reading? }\end{array}$ & & & & & \\
\hline & & $\times 0$ & $\times 1$ & $\times 2$ & $\times 3$ & $\times 4$ \\
\hline
\end{tabular}

Total Score: 


\section{APPENDIX B:}

GLASGOW COMA SCALE 


\section{GLASGOW COMA SCALE}

\begin{tabular}{|c|c|c|c|c|c|c|c|}
\hline $\begin{array}{l}\text { Physical } \\
\text { Response }\end{array}$ & $\begin{array}{c}\text { Points } \\
\text { Assigned }\end{array}$ & 1 & 2 & 3 & 4 & 5 & 6 \\
\hline \multicolumn{2}{|c|}{ Visual Response } & $\begin{array}{c}\text { Eyes } \\
\text { remained } \\
\text { closed }\end{array}$ & $\begin{array}{c}\text { Pain causes eyes } \\
\text { to open }\end{array}$ & $\begin{array}{c}\text { Voices } \\
\text { cause eyes } \\
\text { to open }\end{array}$ & $\begin{array}{l}\text { Eyes open } \\
\text { randomly }\end{array}$ & $\mathrm{N} / \mathrm{A}$ & $\mathrm{N} / \mathrm{A}$ \\
\hline \multicolumn{2}{|c|}{ Verbal Ability } & Silence & $\begin{array}{c}\text { Minimal, } \\
\text { indistinguishable } \\
\text { sounds }\end{array}$ & $\begin{array}{l}\text { Mumbles } \\
\text { obscenities }\end{array}$ & $\begin{array}{l}\text { Incoherent } \\
\text { rambling }\end{array}$ & $\begin{array}{c}\text { Normal } \\
\text { conversation }\end{array}$ & $N / A$ \\
\hline \multicolumn{2}{|c|}{ Motor Skills } & Immobile & $\begin{array}{l}\text { Pain causes } \\
\text { extension } \\
\text { movements }\end{array}$ & $\begin{array}{l}\text { Pain causes } \\
\text { flexion } \\
\text { movements }\end{array}$ & $\begin{array}{c}\text { Pain causes } \\
\text { movement } \\
\text { away from } \\
\text { stimuli }\end{array}$ & $\begin{array}{c}\text { Complicated } \\
\text { movement in } \\
\text { response to } \\
\text { pain }\end{array}$ & $\begin{array}{l}\text { Moves on } \\
\text { command }\end{array}$ \\
\hline
\end{tabular}

